Prepared in cooperation with the California Department of Water Resources

\title{
Measurements of Erosion Potential using Gust Chamber in Yolo Bypass near Sacramento, California
}

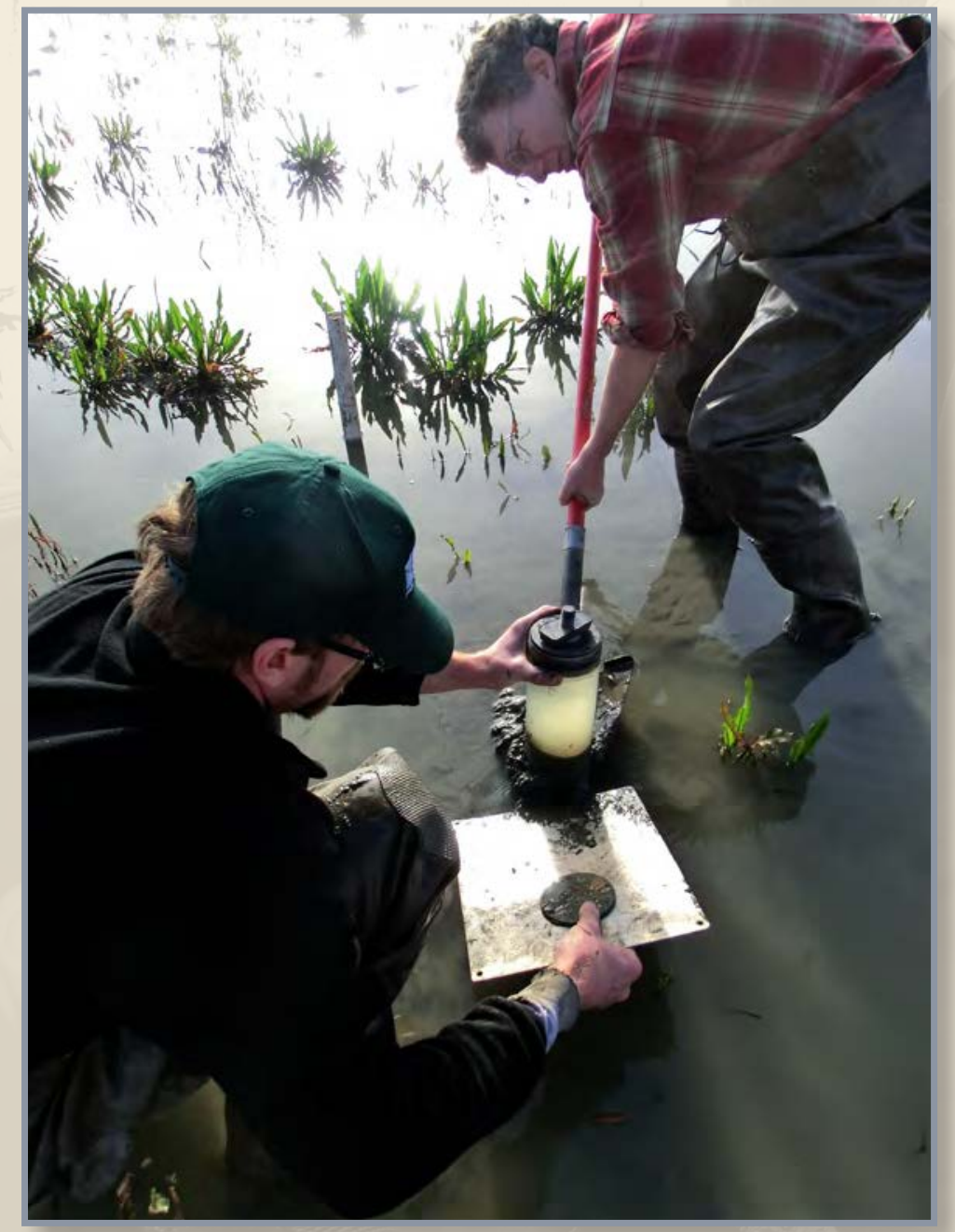

Open File 2018-1062 
Cover photo: Sediment core collection by David Schoellhamer and Kurt Weidich (U.S. Geological Survey). Photograph by Paul Work (U.S. Geological Survey). 


\section{Measurements of Erosion Potential using Gust Chamber in Yolo Bypass near Sacramento, California}

By Paul A. Work and David H. Schoellhamer

Prepared in cooperation with the California Department of Water Resources

Open-File Report 2018-1062 


\title{
U.S. Department of the Interior \\ RYAN K. ZINKE, Secretary
}

\section{U.S. Geological Survey William H. Werkheiser, Deputy Director exercising the authority of the Director}

\author{
U.S. Geological Survey, Reston, Virginia: 2018
}

For more information on the USGS - the Federal source for science about the Earth, its natural and living resources, natural hazards, and the environment-visit https://www.usgs.gov or call 1-888-ASK-USGS.

For an overview of USGS information products, including maps, imagery, and publications, visit https://store.usgs.gov.

Any use of trade, firm, or product names is for descriptive purposes only and does not imply endorsement by the U.S. Government.

Although this information product, for the most part, is in the public domain, it also may contain copyrighted materials as noted in the text. Permission to reproduce copyrighted items must be secured from the copyright owner.

Suggested citation:

Work, P.A., and Schoellhamer, D.H., 2018, Measurements of erosion potential using Gust chamber in Yolo Bypass near Sacramento, California: U.S. Geological Survey Open-File Report 2018-1062, 17 p., https://doi.org/10.3133/ofr20181062. 


\section{Contents}

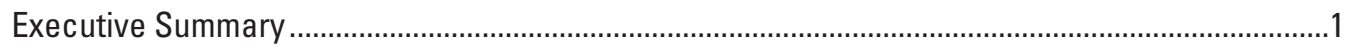

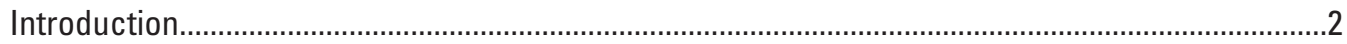

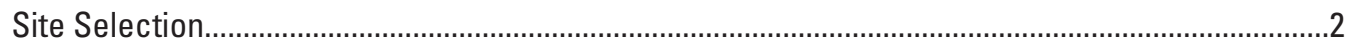

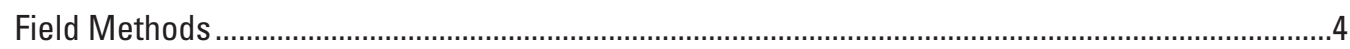

Results

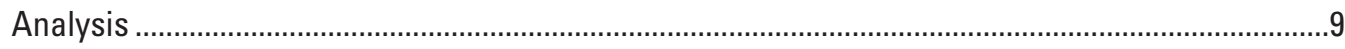

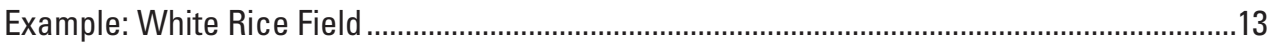

Sediment Sample Analysis................................................................................................13

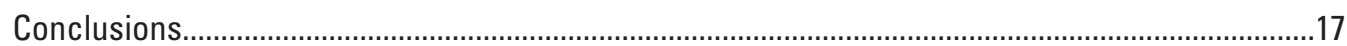

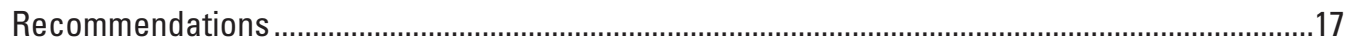

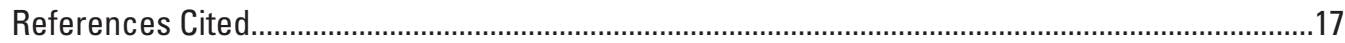

\section{Figures}

1. Map of sites within Yolo Bypass region where U.S. Geological Survey personnel collected cores for analysis of erodibility in Gust chamber................................................

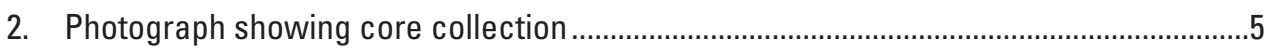

3. Photograph showing two cores with motorized heads installed, ready for testing..........5

4. Graph showing bed shear stress as a function of mean current speed and water depth, assuming no bedforms or vegetation .........................................................

5. Photograph showing Gust chambers set up for measurements .....................................

6. Photograph showing conducting an erosion microcosm experiment in the field immediately after collection of cores...........................................................................7

7. Photographs showing two cores from irrigated pasture site, December 8,2015 .............8

8. Graphs showing time series of microcosm results for two white rice field cores............9

9. Graph showing critical shear stress as a function of eroded mass ................................10

10. Graph showing erosion rate coefficient $M$ as a function of eroded mass ......................11

11. Graph showing mass eroded when the critical shear stress is 0.4 pascal ......................11

12. Graphs showing probabilities of initial critical shear stress and mass eroded when the critical shear stress is $0.4 \mathrm{~Pa}$, for the Yolo Bypass and 38 SacramentoSan Joaquin Delta subtidal cores analyzed 2011-14.....................................................12

13. Diagram showing eroded mass and critical shear stress $\tau_{c}$ are assumed to be

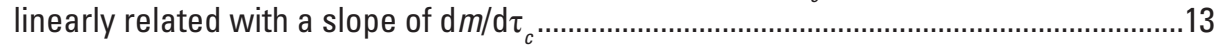

14. Map showing median grain size for sediment samples collected in Yolo Bypass by the California Department of Water Resources...

15. Map showing loss on ignition for sediment samples collected in the Yolo Bypass by the California Department of Water Resources.

16. Map showing percent fines for samples collected in the Yolo Bypass by the California Department of Water Resources 


\section{Tables}

1. Yolo Bypass sites cored for erosion potential tests

2. Initial critical shear stress and slope of relation between eroded mass and shear stress for measured Yolo Bypass land uses, sorted in decreasing order of slope

\section{Conversion Factors}

International System of Units to U.S. customary units

\begin{tabular}{|c|c|c|}
\hline Multiply & By & To obtain \\
\hline \multicolumn{3}{|c|}{ Length } \\
\hline centimeter $(\mathrm{cm})$ & 0.3937 & inch (in.) \\
\hline kilometer (km) & 0.6214 & mile (mi) \\
\hline meter (m) & 3.281 & foot (ft) \\
\hline meter (m) & 1.094 & yard (yd) \\
\hline micrometer $(\mu \mathrm{m})$ & 0.00003937 & inch (in.) \\
\hline millimeter (mm) & 0.03937 & inch (in.) \\
\hline \multicolumn{3}{|c|}{ Area } \\
\hline square meter $\left(\mathrm{m}^{2}\right)$ & 0.0002471 & acre \\
\hline \multicolumn{3}{|c|}{ Volume } \\
\hline cubic meter $\left(\mathrm{m}^{3}\right)$ & 35.31 & cubic foot $\left(\mathrm{ft}^{3}\right)$ \\
\hline cubic meter $\left(\mathrm{m}^{3}\right)$ & 1.308 & cubic yard $\left(\mathrm{yd}^{3}\right)$ \\
\hline \multicolumn{3}{|c|}{ Flow rate } \\
\hline meter per second (m/s) & 3.281 & foot per second (ft/s) \\
\hline \multicolumn{3}{|c|}{ Mass and Weight } \\
\hline kilogram (kg) & 2.205 & pound (lb) \\
\hline \multicolumn{3}{|c|}{ Pressure } \\
\hline kilopascal (kPa) & 0.1450 & pound per square inch $\left(\mathrm{lb} / \mathrm{in}^{2}\right)$ \\
\hline \multicolumn{3}{|c|}{ Density and Unit Weight } \\
\hline kilogram per cubic meter $\left(\mathrm{kg} / \mathrm{m}^{3}\right)$ & 0.06242 & pound per cubic foot $\left(\mathrm{lb} / \mathrm{ft}^{3}\right)$ \\
\hline
\end{tabular}




\section{Datum}

Horizontal coordinate information is referenced to the North American Datum of 1983 (NAD 83).

Elevation is referenced to the North American Vertical Datum of 1988 (NAVD 88).

\section{Abbreviations}

DWR California Department of Water Resources

SSC suspended sediment concentration

USGS U.S. Geological Survey

\section{Definition of Terms}

$D_{90} \quad$ 90th percentile grain size (size such that 90 percent of sample is finer), $\mathrm{mm}$

$E(m, t)$ erosion rate, $\mathrm{kg} / \mathrm{m}^{2} / \mathrm{s}$

$H \quad$ water depth, $\mathrm{m}$

$k_{s} \quad$ bed grain size roughness height, $\mathrm{mm}$

$\kappa \quad$ von Karman constant (dimensionless)

$m \quad$ eroded mass, $\mathrm{kg} / \mathrm{m}^{2}$

$M(m)$ erosion rate coefficient, $\mathrm{kg} / \mathrm{m}^{2} / \mathrm{s} / \mathrm{Pa}$

$\rho \quad$ water density, $\mathrm{kg} / \mathrm{m}^{3}$

$\tau_{b} \quad$ bed shear stress, $\mathrm{Pa}$

$\tau_{c} \quad$ critical shear stress (stress required to initiate erosion), $\mathrm{Pa}$

$\tau_{c 0} \quad$ initial value of critical shear stress, $\mathrm{Pa}$

U flow speed, $\mathrm{m} / \mathrm{s}$

$u_{*} \quad$ shear velocity, $\mathrm{m} / \mathrm{s}$ 



\title{
Measurements of Erosion Potential using Gust Chamber in Yolo Bypass near Sacramento, California
}

\author{
By Paul A. Work and David H. Schoellhamer
}

\section{Executive Summary}

This report describes work performed to quantify the erodibility of surface soils in the Yolo Bypass (Bypass) near Sacramento, California, for use in the California Department of Water Resources (DWR) Yolo Bypass D-MCM mercury model. The Bypass, when not serving as a floodway, is heavily utilized for agriculture. During flood events, surface water flows over the soil, resulting in the application of a shear stress to the soil. The shear stress is a function of flow speed and is often assumed to vary as the square of flow speed. Once the shear stress reaches a critical value, erosion commences, and the erosion rate typically increases with applied shear stress. The goal of the work described here was to quantify this process and how it varies throughout the major land uses found in the Yolo Bypass.

Each of the major land uses found in the Bypass was targeted for sediment coring and two side-by-side cores, 10 centimeters in diameter, were extracted at each site for testing in a Gust erosion chamber. This device consists of a cylinder with a piston and cap installed to contain a sediment sample and overlying water. In most instances, coring was done with the cylinder, the piston and cap were installed, and testing commenced immediately. The cap at the top of the cylinder contains vanes to induce rotation of the flow and is driven by an electric motor, simulating the bed shear stress experienced by the soil in a flood event. Ambient water is introduced to the cylinder, passes through the device, and carries eroded sediment out of the chamber. The exiting water is tested for turbidity, and water samples obtained to relate turbidity to suspended-sediment concentration are used to compute erosion rates for each of the applied shear stresses.

The result for each sediment core is (1) definition of the critical shear stress required to initiate sediment erosion and (2) estimation of coefficients required to relate erosion rate to applied shear stress once this critical shear-stress threshold has been exceeded. These quantities were computed for each of the sites sampled. In total, 10 locations were sampled, representing 10 land uses ranging from wild and white rice fields to the flooded Liberty Island and the Toe Drain that receives runoff from much of the cultivated land (table 1).

The Gust chamber test causes the erosion of a very small layer of sediment, typically less than a millimeter thick. The strength of the soil within this layer increases with depth, typically, and this soil strength versus depth is measured in the testing process.

Results for each land use type tested are presented as the initial critical shear stress at which erosion began and the rate at which erosion increases as shear stress increases (table 2). Of the land use types sampled, irrigated pasture displayed the lowest critical shear stress, meaning that it required the smallest flow speed to initiate erosion. But in this case, the rate of increase of the subsequent erosion, given higher flow speeds, was small. The wild rice field samples exhibited a higher critical shear stress but also exhibited a much higher erosion rate once the critical shear stress was exceeded. The erosion rate for wild rice was about three times greater than that for white rice. Bear in mind that these results are based on only two cores tested per site, and variability between fields with the same crop could be significant. Approved digital data can be viewed and downloaded from ScienceBase, at https://doi.org/10.5066/F7BV7DQC. These results are being used to calculate erosion rates in the DWR Yolo Bypass D-MCM mercury model.

The Toe Drain was very difficult to sample, owing to hard, consolidated sediments on the channel bed. On the first visit, two cores were obtained successfully, and testing revealed very different results. A second visit was made, but it was not possible to obtain cores suitable for testing with the coring equipment used. The available results suggest that Toe Drain soil is highly erodible (low critical shear stress and high erosion rate once initiated) despite being difficult to sample. As a collector of runoff, it also has the potential to accumulate soils eroded from adjacent areas, subsequent to storm events, as flows subside. This deposited material will typically be more erodible than the material that it lands on. The deposition and resuspension of material was not simulated in the testing described here because the applied shear stress increases monotonically during testing. 
The spatial distribution of mean grain size, loss on ignition, and percent fines of Yolo Bypass soils are also presented. Sediment sampling for this effort was performed by DWR; the U.S. Geological Survey (USGS) performed the sample analysis. These data should thus be considered provisional, but the remainder of the data presented here, and this report, have been through the formal U.S. Geological Survey review process.

A separate effort has been made by others to develop numerical model results defining the spatially varying, timedependent hydrodynamics in the Yolo Bypass. These model results are being used to quantify shear stress on the soil surface, which together with the Gust chamber results shown here, are used for the DWR Yolo Bypass D-MCM mercury transport model to compute erosion rates for each time step.

\section{Introduction}

Mercury adsorbs to sediment, especially fine sediment, and there are concerns (Alpers and others, 2014) about deposits of mercury-rich sediment in the Yolo Bypass, which serves as a floodway to protect the city of Sacramento, California. Potential movement and transformation of mercury is being investigated by a California Department of Water Resources (DWR) numerical modeling effort, supported by field measurements to provide input to the model.

The usefulness and suitability of the mercury transport model (DWR Yolo Bypass D-MCM mercury model) results depend partly on the accuracy and resolution with which the initial mercury levels are quantified and the methods by which erosion is simulated. The erosion of cohesive sediments is initiated once a critical shear stress on the bed is exceeded, with applied shear stress being primarily dependent on flow speed, water depth, and bed material and configuration. The rate at which erosion proceeds is dependent on (1) the sediment itself and (2) the shear stress applied to it in excess of the critical shear stress. So it is necessary to quantify (1) the critical shear stress, which will vary from place to place and in time, and (2) the erosion rate for a variety of applied shear stresses. The U.S. Geological Survey (USGS), in cooperation with the California Department of Water Resources, used a Gust erosion chamber to accomplish this.

The Yolo Bypass has a variety of land uses, many of them agricultural. The sampling described here was intended to yield results at sites representing the most representative land uses. Time and budget constraints limited the number of samples that could be tested, but at least two results were obtained at sites representing each of the major land uses, including white rice fields, wild rice fields, fallow fields, and natural and constructed wetland environments.

Some of the results shown in this report are based on provisional data, subject to revision, but most have been reviewed and released on ScienceBase (see Work and others, 2016, at https://doi.org/10.5066/F7BV7DQC).

\section{Site Selection}

In total, 10 locations were sampled, representing 10 land uses ranging from wild and white rice fields to the flooded Liberty Island and the Toe Drain that receives runoff from much of the cultivated land. As noted above, sites were chosen to span the principal land use types found in the Yolo Bypass. A map showing locations of the sampled sites is shown in figure 1; site details are presented in table 1 .

Most sites were terrestrial, or featured only shallow water, allowing access by foot and manual push coring. A few sites (such as the Liberty Island and Toe Drain sites) were accessed by boat and sampled using a gravity corer. With the exception of the Toe Drain and Liberty Island, all samples were collected soon after harvest or following initial managed flooding (seasonal wetlands) so that our erosion results would provide information on the antecedent erosion conditions in the Bypass during winter when a flood is most likely. Sampling details are presented in the section "Field Methods" section of this report. 


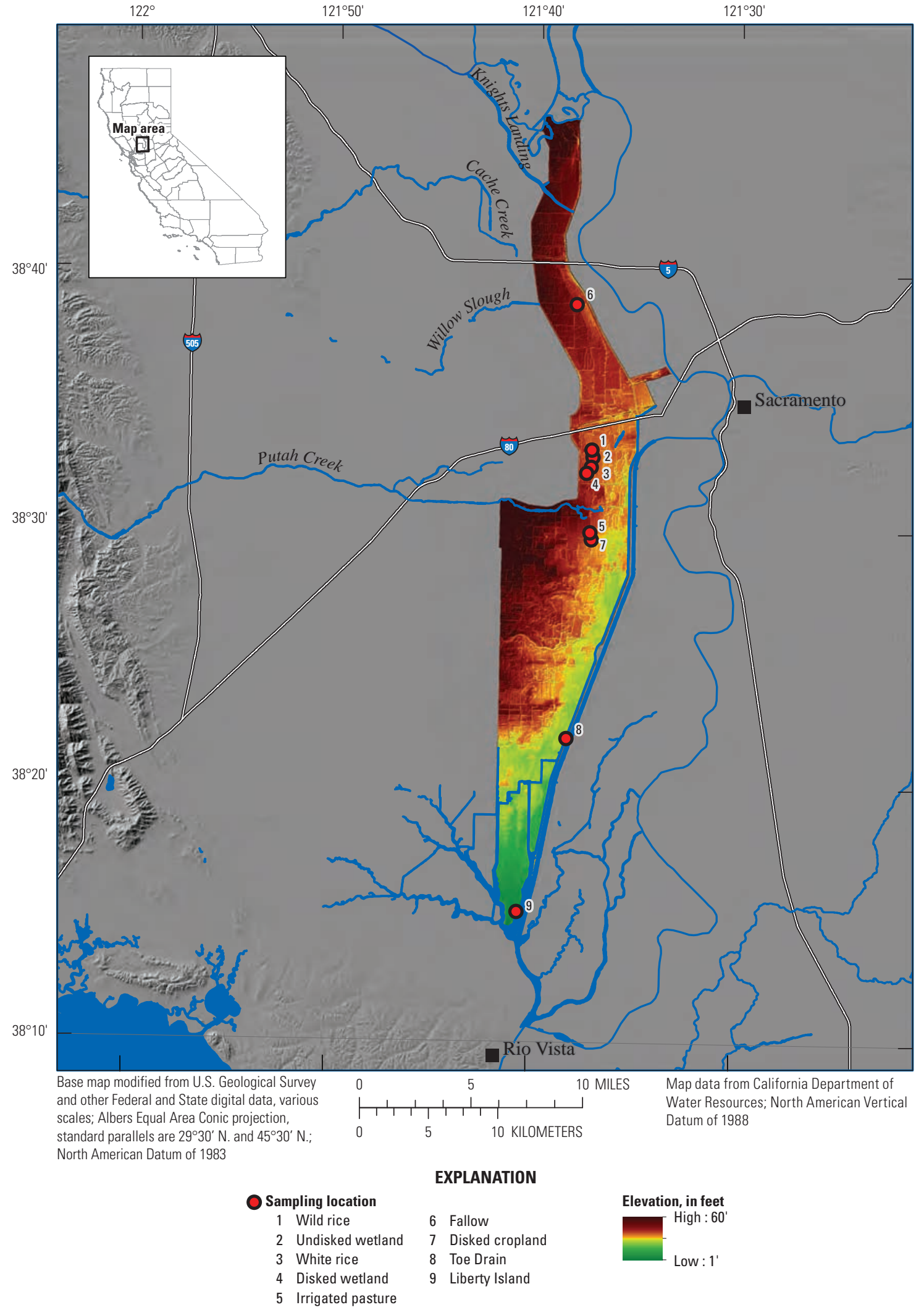

Figure 1. Sites within Yolo Bypass region where U.S. Geological Survey personnel collected cores for analysis of erodibility in Gust chamber. 
Table 1. Yolo Bypass sites cored for erosion potential tests.

[Two cores were taken and tested at each site. Abbreviation: mm/dd/yyyy, month/day/year]

\begin{tabular}{lccccc}
\hline \multicolumn{1}{c}{ Land use } & $\begin{array}{c}\text { Date } \\
\text { (mm/dd/yyy) }\end{array}$ & $\begin{array}{c}\text { Latitude North } \\
\text { (degrees) }\end{array}$ & $\begin{array}{c}\text { Latitude North } \\
\text { (minutes) }\end{array}$ & $\begin{array}{c}\text { Longitude West } \\
\text { (degrees) }\end{array}$ & $\begin{array}{c}\text { Longitude West } \\
\text { (minutes) }\end{array}$ \\
\hline Wild rice & $01 / 30 / 2015$ & 38 & 32.864 & 121 & 37.173 \\
Undisked wetland & $02 / 04 / 2015$ & 38 & 32.472 & 121 & 37.237 \\
White rice & $02 / 27 / 2015$ & 38 & 33.149 & 121 & 37.22 \\
Disked wetland & $03 / 05 / 2015$ & 38 & 32.234 & 121 & 37.472 \\
Irrigated pasture & $12 / 08 / 2015$ & 38 & 29.647 & 121 & 37.175 \\
Conaway fallow & $02 / 04 / 2016$ & 38 & 38.81 & 121 & 38.096 \\
Los Rios disked cropland & $02 / 23 / 2016$ & 38 & 29.921 & 121 & 37.259 \\
Los Rios disked cropland; saturated before testing & $02 / 29 / 2016$ & 38 & 29.921 & 121 & 37.259 \\
Toe Drain & $04 / 26 / 2016$ & 38 & 21.879 & 121 & 38.268 \\
Liberty Island & $01 / 06 / 2017^{*}$ & & & & 40.588 \\
\hline
\end{tabular}

${ }^{*}$ Coring was unsuccessful on this date (bed material too hard to sample with gravity corer).

\section{Field Methods}

Field methods are similar to those described by Dickhudt and others (2011) and used previously in the SacramentoSan Joaquin Delta (Delta; Schoellhamer and others, 2017). Where personnel had direct access to the soil being sampled, push coring was used to acquire two sediment cores, using 10-centimeter (cm) diameter cylinders (fig. 2). Many sample locations had $0-30 \mathrm{~cm}$ of standing water overlying the sampled soil, facilitating this approach. Samples were disturbed as little as possible during coring. The top $1 \mathrm{~cm}$ of soil adjacent to the core was also sampled for grain size and water content analyses. A piston inserted into the bottom of the cylinder was used to push the sediment surface up to within $10 \mathrm{~cm}$ of the top of the cylinder. This piston was sealed to prevent loss of water or sediment from the bottom of the chamber.

To proceed with testing, the core was installed in a stand and a motorized head added to the top (fig. 3). The head serves two purposes: (1) it contains a motorized disk that causes the fluid in the chamber to rotate, resulting in a shear stress on the bed, and (2) it both introduces ambient water to the chamber and removes water from the chamber that has picked up sediment from the bed by way of erosion. The exiting water was sampled periodically for sediment analysis to allow determination of a relationship between turbidity and suspended-sediment concentration. This exiting flow was not returned to the measurement system-it simply flowed into a receiving bucket and was later discarded.
The rotating flow, by itself, would be fastest at the wall of the cylinder and have zero speed at the center of the cylinder. The water that is introduced to the chamber (by pumping from a bucket of ambient water) travels from the outside of the cylinder towards the center, speeding up as it proceeds towards the center (in fluid mechanics, this is referred to as "sink flow," similar to how water flows towards a drain in a sink). Together, the rotating and sink flows add up to create a more uniform flow speed across the bed surface, and therefore more uniform bed shear stresses, than either one of them would create individually. This is important because it is assumed that the core being tested is (essentially) homogeneous and experiences homogeneous conditions.

A flow passing along a rigid boundary exerts a shear stress on that boundary that is dependent on the flow speed, the roughness of the surface, and the viscosity of the fluid. The relation between rotation speed, pumping rate, and shear stress for the apparatus was determined empirically by the manufacturer (Suttles and others, 2011). Viscosity does not vary significantly with temperature for the conditions encountered at the sites considered here, and the collected samples had a nearly flat bed surface with minimal ripples. So for each case, knowing the rotational speed, it was possible to look up the corresponding bed shear stress. Note that while shear stress does increase with flow speed, the relationship between the two is not linear, or unique. Changes in viscosity or roughness, for example, can modify bed shear stress even without a change in flow speed. 


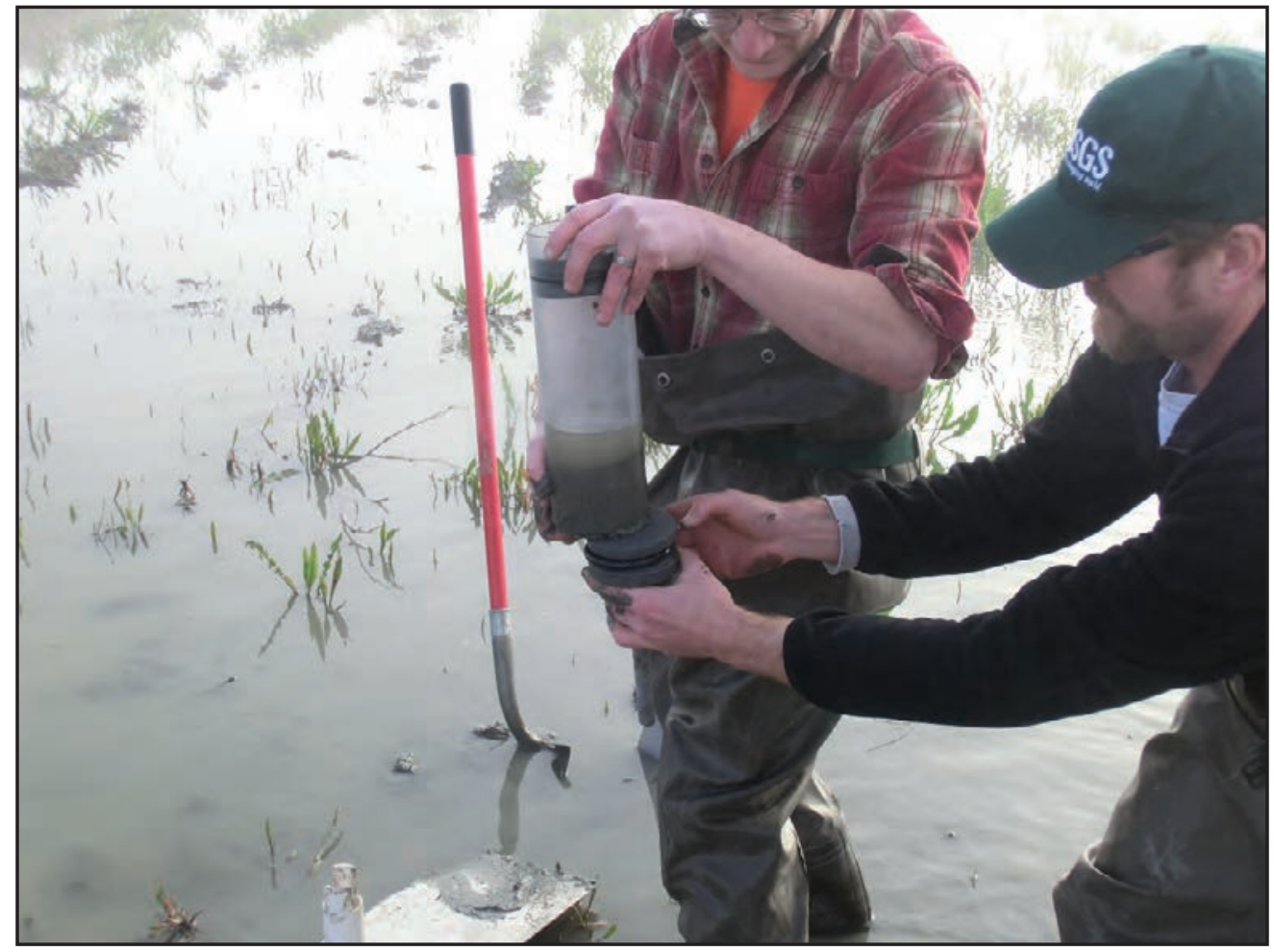

Figure 2. Core collection. The coring tube is pushed manually into the soil and an aluminum plate slid beneath it to facilitate extraction. Then a piston is inserted from below. The soil sample is pushed up to within 10 centimeters of the top of the cylinder.

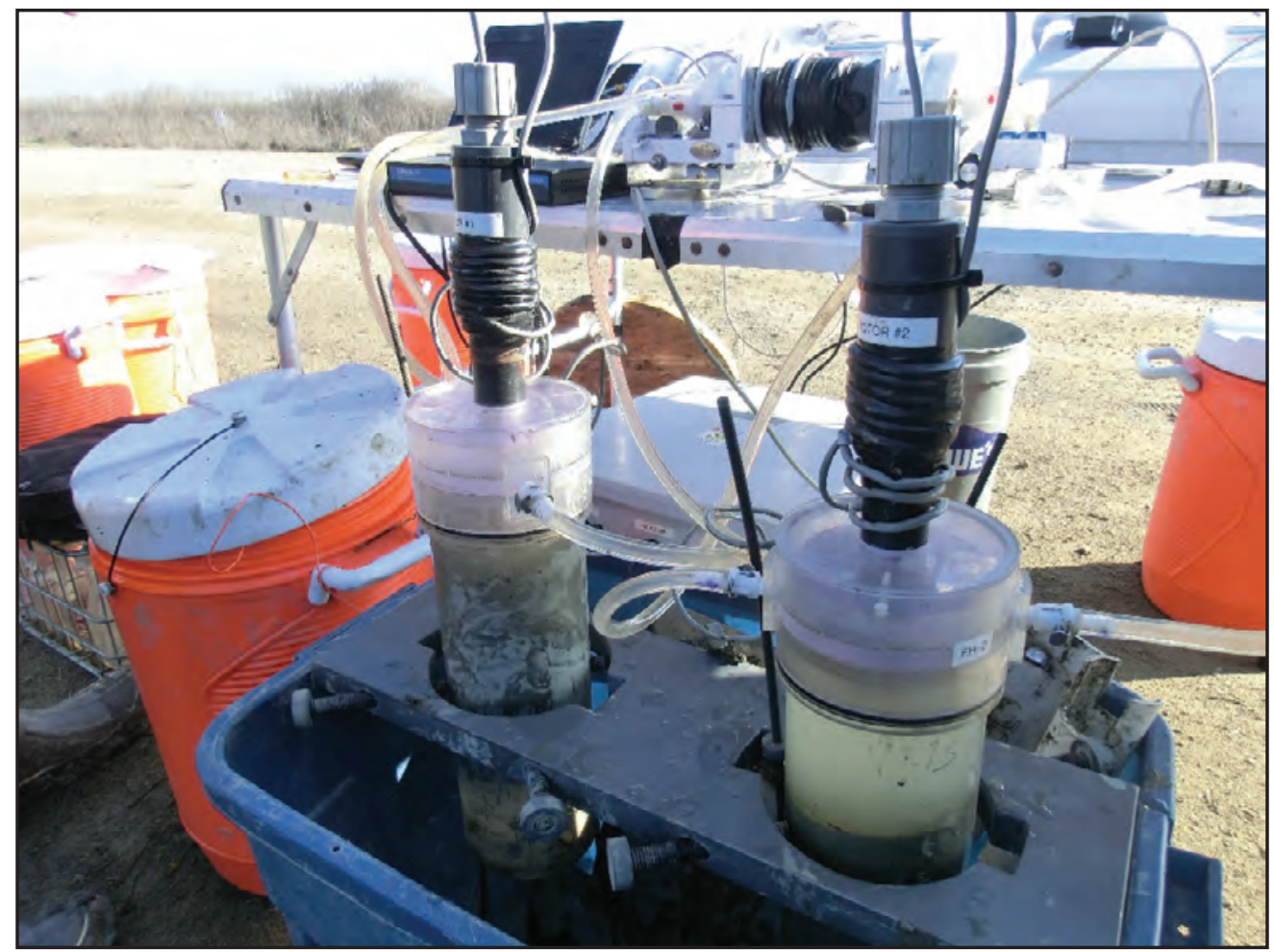

Figure 3. Two cores with motorized heads installed, ready for testing. The smaller diameter black cylinders above the clear cylinders are the motors that drive the rotating disks. The apparatus used for this testing is often referred to as a Gust chamber or Gust Erosion Microcosm System (U-GEMS). It was obtained from Green Eyes LLC. 
Tests were initiated at very low shear stresses ( 0.01 pascal $[\mathrm{Pa}]$, where $1 \mathrm{~Pa}=1$ newton per square meter). The introduced water flowed through the cylinder and then out through a turbidimeter used to monitor the turbidity of the effluent, which was not reintroduced to the chamber. This initial shear stress was maintained until equilibrium was observed, meaning that observed turbidity was nominally constant at the level of the ambient water entering the chamber. The rotational speed of the disk was then gradually increased to raise the bed shear stress, $\tau_{b}$, in stepwise fashion to $0.05,0.10,0.15,0.20$, $0.30,0.45$, and 0.60 Pa over a period of about 3 hours. Water samples were collected from the effluent during each step to allow later analysis for suspended-sediment concentration (SSC). This allows for conversion of observed turbidity to suspended sediment transport concentration (and mass erosion rate). The SSC of the inflowing water is assumed to be the minimum observed SSC at the outflow. The end result is a relationship between applied bed shear stress (force per unit area) and erosion rate (eroded mass per unit time per unit area).

Applied shear stress, $\tau_{b}$, and depth-averaged velocity, $U$, can be related as follows, for a scenario lacking bedforms or other flow obstructions. The American Society of Civil Engineers (Garcia, 2008) provide equations 1-3:

$$
\begin{gathered}
U / u_{*}=1 / \kappa \ln \left(11 H / k_{s}\right) \\
u_{*}=\left(\tau_{b} / \rho\right)^{1 / 2} \\
k_{s}=3 D_{90}
\end{gathered}
$$

where

$$
\begin{array}{cl}
u_{*} & \text { is the shear velocity, } \\
\kappa & \text { is the von Karman constant equal to } 0.4, \\
H & \text { is the water depth, } \\
k_{s} & \text { is the bed grain size roughness height, } \\
\rho & \text { is the density of water (1,000 kilograms per } \\
& \text { cubic meter; } \left.\mathrm{kg} / \mathrm{m}^{3}\right) \text {, and } \\
D_{90} & \text { is the } 90 \text { th percentile by mass of grain size. }
\end{array}
$$

Water viscosity does not appear explicitly but influences the bed shear stress.

A representative relation between $U$ and $\tau_{b}$ is shown in figure 4 . Note that this example assumes negligible impacts of vegetation and bedforms.

Note that with the relatively shallow depths (order of magnitude of 1 meter) frequently encountered in the Yolo Bypass, any flow speeds exceeding $\sim 0.7$ meters per second $(\mathrm{m} / \mathrm{s}$; 2.3 feet per second) will result in shear stress on the bed (eqs. 1-3) that exceeds the 0.6-Pa maximum that was encountered in the Gust chamber. Put another way, for flow speeds above $0.7 \mathrm{~m} / \mathrm{s}$, use of the results shown here means that one is extrapolating outside of the region for which the approach was calibrated, which is generally not recommended. In order to evaluate the area of the Yolo Bypass experiencing shear stresses exceeding 0.6 $\mathrm{Pa}$, the authors were provided with a snapshot of velocities from the TUFLOW model results generated for this study, corresponding to the biggest flow and highest shear stress being simulated (January 2, 1997). Under these extreme conditions, only 30.3 percent of the Yolo Bypass experienced flow speeds outside of the range of applicability of the results shown in this report.

Two cores were taken per site, to help assess variability, with attempts being made to avoid heavy vegetation, which can make both sample acquisition and testing difficult. Testing was done in the field immediately after sample collection (figs. 5, 6).

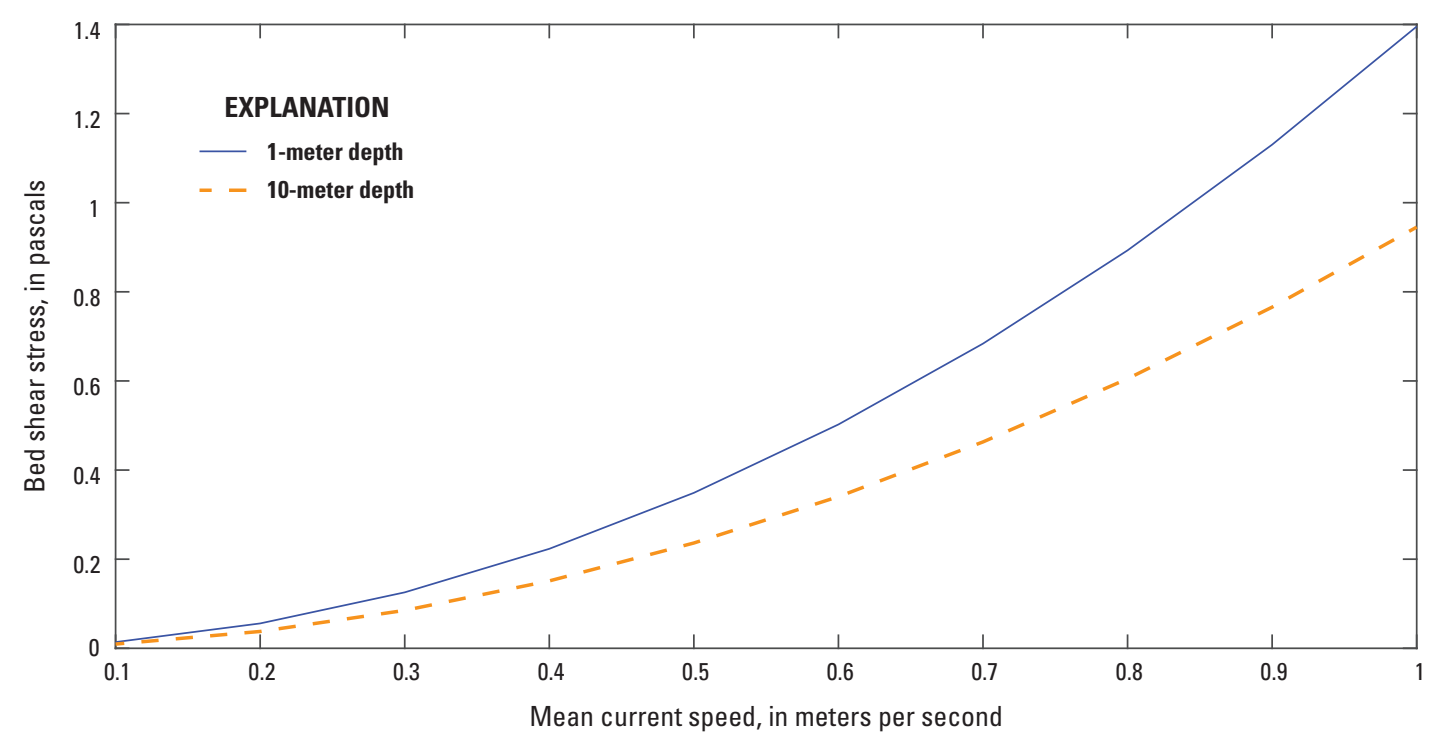

Figure 4. Bed shear stress as a function of mean current speed and water depth, assuming no bedforms or vegetation. This figure is derived from equations $1-3$ using a representative $D_{90}$ (90th percentile by mass of grain size) of 82 micrometers and for water depths of 1 and 10 meters. 


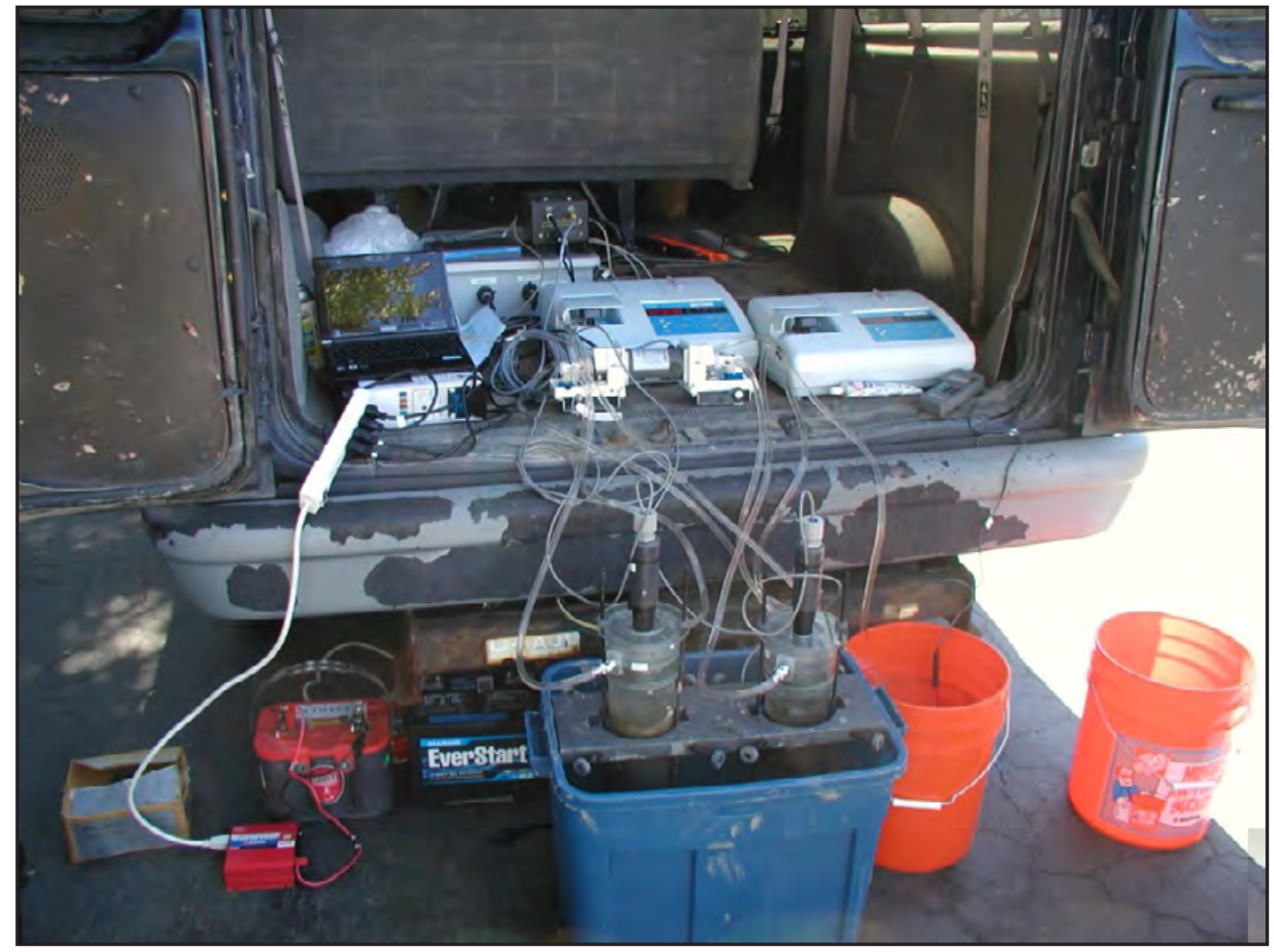

Figure 5. Gust chambers (twin cylinders mounted in plate suspended on blue box) set up for measurements. On the back of the van are two turbidimeters to measure turbidity of the effluent from the erosion chambers. This effluent was sampled periodically to obtain samples for analysis for suspended sediment concentration.

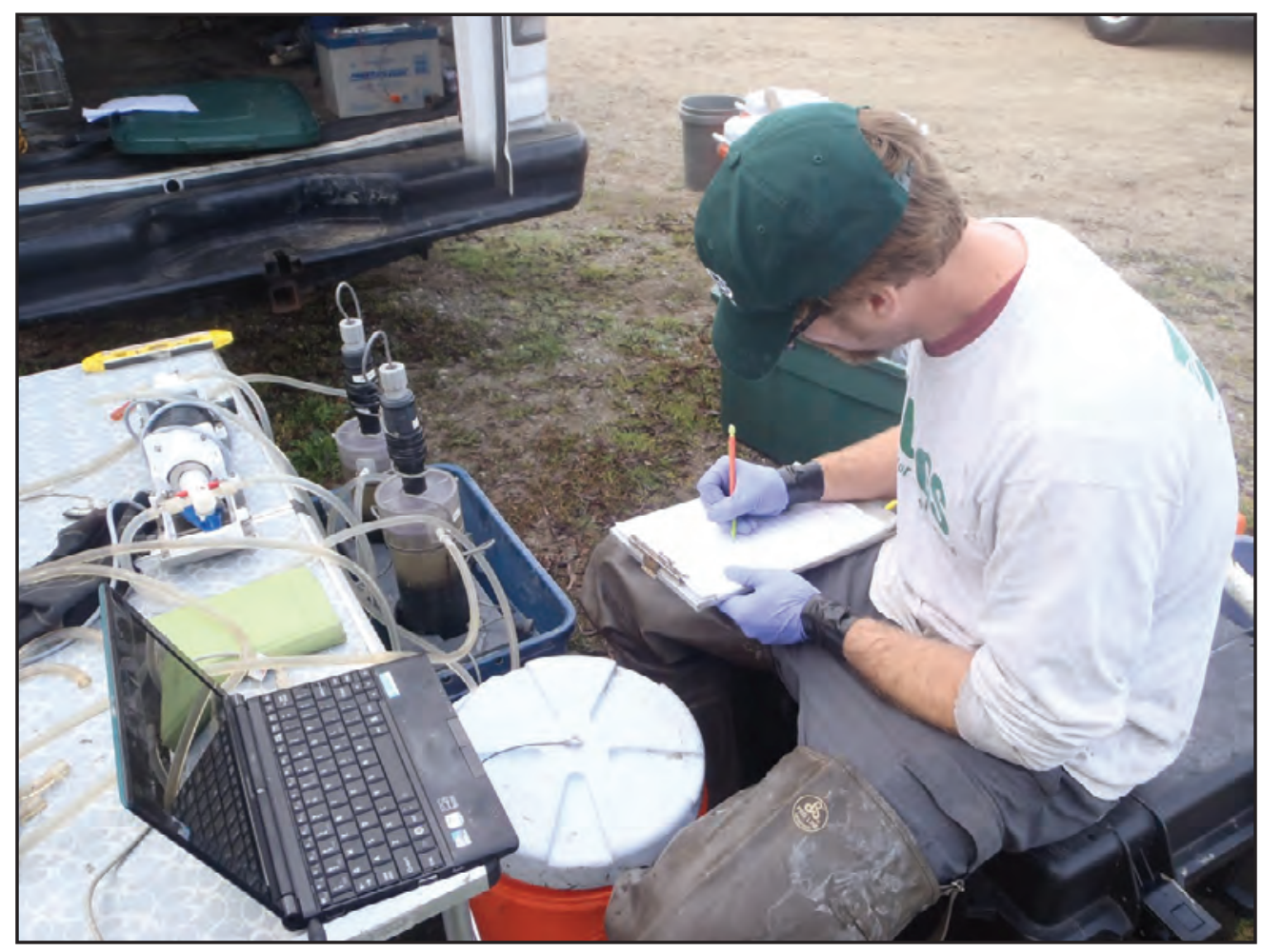

Figure 6. Conducting an erosion microcosm experiment in the field immediately after collection of cores. On top of the table are a computer that collects data and controls the experiment and the pump. On the ground are the two cores being eroded (the erosion chambers) and a cooler supplying the ambient water being pumped through the erosion chambers. 
In total, 10 different sites/land uses were tested in the Yolo Bypass. It is not feasible to span all land uses and soil conditions found in in the Yolo Bypass, so sites with the most common land uses (as defined by the Yolo Bypass D-MCM model), high mercury content, and fine grain size were selected.

The irrigated pasture site, unlike the other land uses, was so heavily vegetated that it was not possible to acquire vegetation-free cores. Each core had dense clover, and it was decided to test the two cores in slightly different ways. The first was tested without any preparation, whereas the second was prepared by close cropping the vegetation with a pair of scissors (fig. 7). The thick vegetation in the unmodified core will significantly modify (reduce) the shear stress experienced by the underlying bed, and it was hypothesized that this would effectively prevent erosion. Not only was this found to be the case, even the closely cropped core featured miniscule erosion, likely because of the roots helping to protect the bed from erosion. Based on these results, it was recommended that heavily vegetated areas be treated as unerodible in the model, lacking information to the contrary.

In this sense, the microcosm results are conservative in that they represent the upper bound on erosion rate for a given shear stress on a given soil sample. In addition, both the fluid-induced shear stress in the field and the soil's resistance to erosion can display significant spatial variability. Crop furrows, for example, will lead to spatial variations in turbulence and shear stress on the bed. It should also be remembered that the test results define erosion potential - the actual erosion rate depends on the actual flows encountered by the soil, which in the case of this Yolo Bypass study are being defined by numerical model results. Also, as shear stress is reduced following an erosion event, there is the potential for material to be deposited back onto the bed. This process is not simulated in the erosion chamber, which best represents initial flooding of the Bypass when flows are increasing.

\section{Results}

The raw data collected in the field include rotational speed of the motor and turbidity of the water flowing out of the chamber. The water samples collected periodically from the effluent are processed later in the lab to determine (gravimetrically) the concentration of suspended sediment at each time step. This allows the development of an empirical relationship between turbidity and suspended-sediment concentration (SSC) for the site.

Figure 8 provides an example of the raw and processed data from one location at which the most recent land use was cultivation of white rice. The stepwise increase in shear stress, computed from motor rotational speed, during the erosion experiment is shown in figure $8 \mathrm{~A}$. The mean value is shown for each motor speed increment, but the standard deviation of the shear stress in the microcosm is about 11 percent of the mean (Gust and Muller, 1997). Estimated SSC, which decreases to a background level and then increases when shear stress rises from 0.2 to $0.3 \mathrm{~Pa}$ and erosion in both cores begins, is shown in figure $8 B$. The initial critical shear stress for erosion is taken as the midpoint between these two stress levels, or $0.25 \mathrm{~Pa}$. The mean error of the turbidity to SSC calibration was 13 percent for the white rice cores and all eight cores eroded in 2015.

\section{A. Unmodified core}

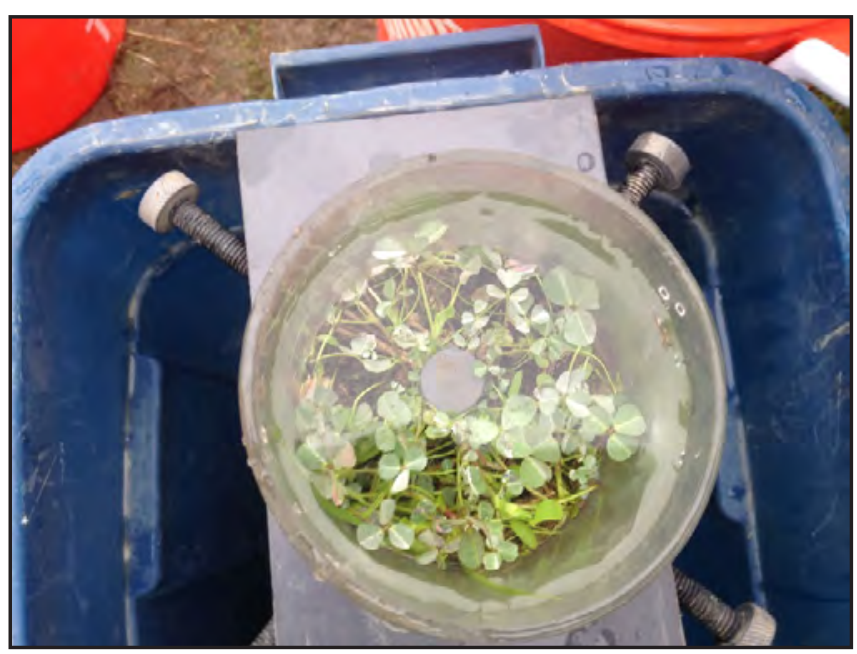

\section{$B$. Prepared by close cropping with a pair of scissors}

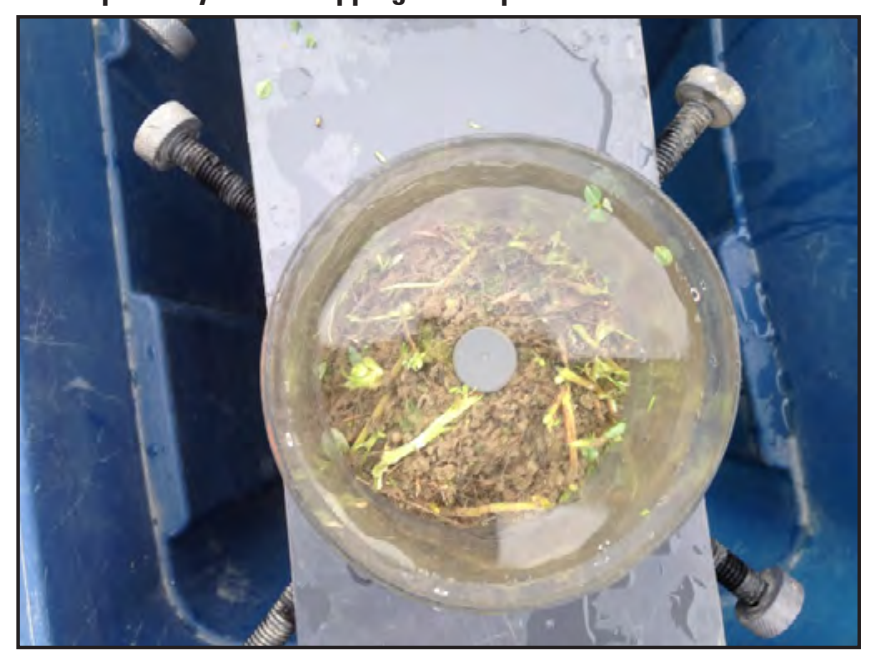

Figure 7. Two cores from irrigated pasture site, December 8, 2015. $A$, unmodified core and $B$, core prepared by close cropping with a pair of scissors. 
The time series of erosion rate, $E$, calculated from SSC, flow rate through the chamber, and the geometry of the chamber are shown in figure $8 \mathrm{C}$. Multiplying the difference between the outflowing and inflowing sediment mass concentration times the volume flow rate gives a net mass flow rate out (mass per unit time), and dividing this by area of the core gives an erosion rate in mass per unit time per unit area.

Erosion rate increases rapidly at the beginning of each shear stress step greater than the initial critical shear stress and then decreases until the next increase in shear stress. This behavior indicates depth-limited erosion for which only a limited amount of mass can be eroded for each shear stress. The SSC calibration error and typical flow rate error (difference between actual flow rate and flow rate required to obtain desired bed shear stress) of about 1-4 percent contribute to the error in erosion rate.

\section{Analysis}

The results shown in figure 8 are empirical and derived from measurements in the field. In order to use them within a predictive model, an equation relating erosion rate to eroded mass is required.

The erosion model of Sanford and Maa (2001) was used to calculate erosion parameters and relate shear stress and erosion rate. The erosion rate $(E)$ for an experiment as a function of mass eroded $(m)$ and time $(t)$ is

$$
E(m, t)=M(m)\left[\tau_{b}(t)-\tau_{c}(m)\right]
$$

where $M$ is an empirical coefficient that depends on eroded mass $m$. The term within the brackets is the difference between the actual and critical values of the bed shear stress and is often referred to as excess shear stress.

The eroded mass included here, $m$, can be viewed as a proxy for depth into the sediment bed: as more and more mass is eroded, the bed surface is deflated, although the relationship between eroded depth and eroded mass will typically be nonlinear because bed density typically increases with depth into the bed. Note that the eroded depths in the tests are extremely small and not visible to the naked eye. As an example, in figure 8, an eroded mass of 0.1 kilograms per square meter $\left(\mathrm{kg} / \mathrm{m}^{2}\right)$ is typical by the end of the test. With soil density somewhere between 1,000 (water) and $2,500 \mathrm{~kg} / \mathrm{m}^{3}$, this corresponds to only a fraction of a millimeter of soil depth.

The critical shear stress, $\tau_{c}$, is calculated at the end of each step of applied bed shear stress, $\tau_{b}$, and is assumed to increase with eroded mass $m$, which in turn increases with erosion depth. The coefficient $M(m)$ is assumed to be a constant for each step.
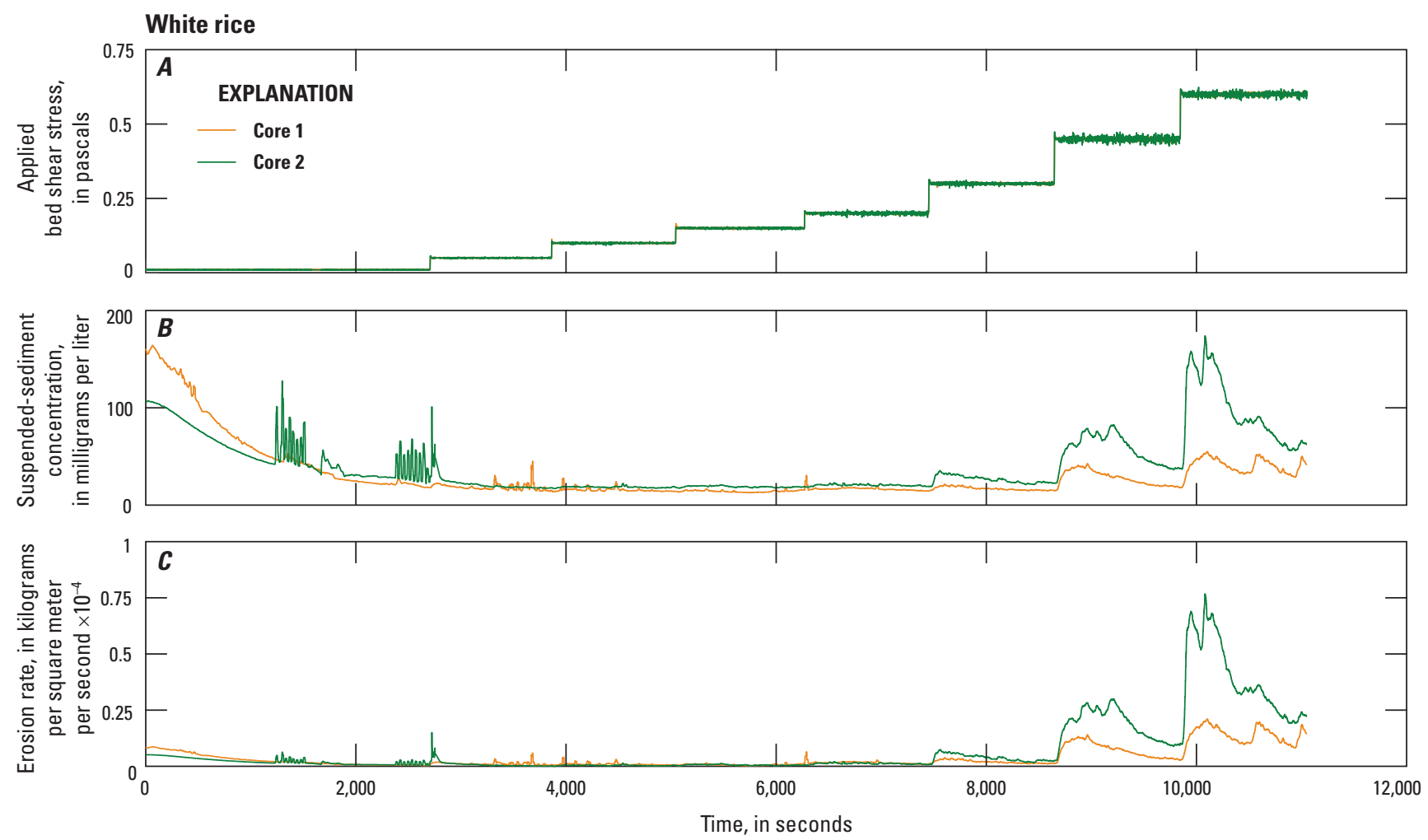

Figure 8. Time series of microcosm results for two white rice field cores. $A$, applied bed shear stress, $\tau_{b^{\prime}} B$, suspended sediment concentration, SSC; and $C$, erosion rate, E. Entire experiment spanned roughly 3 hours. 
With this information, the erodibility, defined by $\tau_{c}$ and $M$, of the study sites relative to one another can be determined. Critical shear stress increases as the eroded mass increases (fig. 9). Eroded mass and mean erosion depth covary, so figure 9 shows that critical shear stress increases as erosion depth increases. The erosion constant $M$ also generally increases with eroded mass or mean erosion depth (fig. 10). Typically, $M$ has more variability than $\tau_{c}$ as seen in figures 9 and 10. The general increase in $M$ with eroded mass may be due to small erosion depths and horizontal variability of critical shear stress (Schoellhamer and others, 2017). These parameters constrain erosion rates in the mercury model because the erodibility of each model box relative to the others is known. Thus, the erosion time series can be multiplied by a single calibration factor to achieve model calibration.

A simple way to compare the relative erodibility of the land use types is to compare the mass eroded when the critical shear stress reaches $0.4 \mathrm{~Pa}\left(m_{0.4}\right.$; see fig. 11 ; see Dickhudt and others, 2011). The variability between replicate cores for a given land use type and between land use types are similar on a logarithmic scale. Each land use type has only two replicate cores, so statistical tests of significance are not possible. The data graphically indicate that irrigated pasture is less erodible than the other land use types and the Toe Drain is more erodible than other land use types.
Note in figures 9-11 that each core yields a unique result. In some cases, the two results are quite similar; in others, the computed erosion rates differ by a factor of two or more. Although every measurement contains some error, the primary contributor to these large differences is the heterogeneity of the soil samples collected, which include surface undulations, holes, and roots. Even if the measurements were acquired with zero uncertainty, there is still a range of values of erosion rate, for a given shear stress, that should be considered for a given land use.

Erosion parameters from the Yolo Bypass can be compared to those found for 38 subtidal cores from the Delta (Schoellhamer and others, 2017). Comparing initial critical shear stress (fig. 12, left panels), half of the Yolo Bypass cores tested had an initial critical shear stress of $0.25 \mathrm{~Pa}$, which is larger than typically found in the subtidal Delta. The mass eroded when the critical shear stress is equal to $0.4 \mathrm{~Pa}$ (fig. 12, right panels) is comparable between the Yolo Bypass and Delta. Thus, the Yolo Bypass cores generally had a greater erosion threshold but would erode a similar quantity of mass if the applied shear stress were a constant 0.4 Pa. Tillage, greater sunlight, and ponded water rather than tidally flowing water may account for these differences.

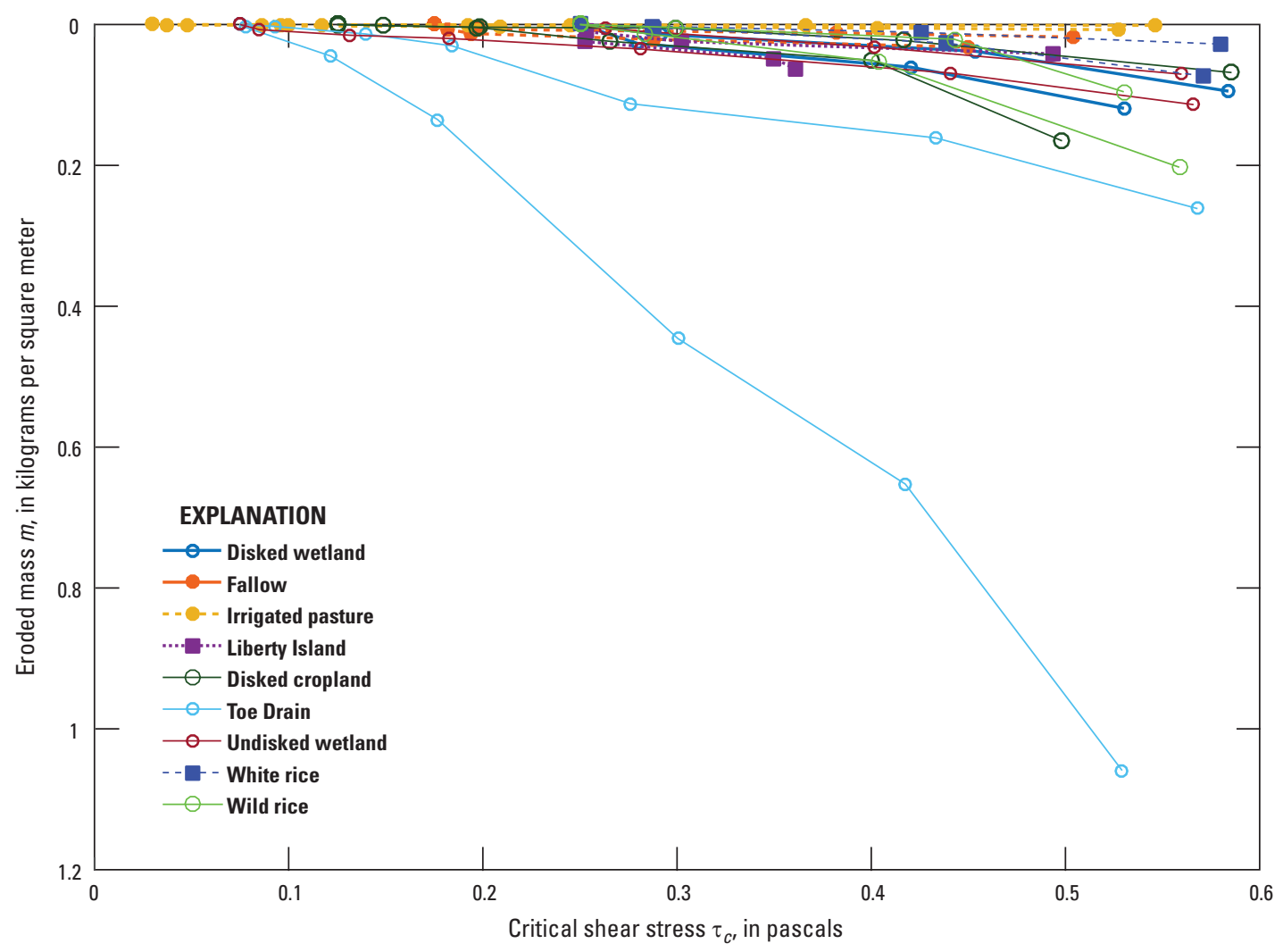

Figure 9. Critical shear stress as a function of eroded mass. As mass is eroded, bed elevation is reduced, so the $y$-axis can be viewed as a (nonlinear) proxy for depth into the bed. Also note that one of the cores at the irrigated pasture site featured heavy vegetation that resulted in overestimation of the actual bed shear stress. Erosion rate was extremely small for this core, however. 


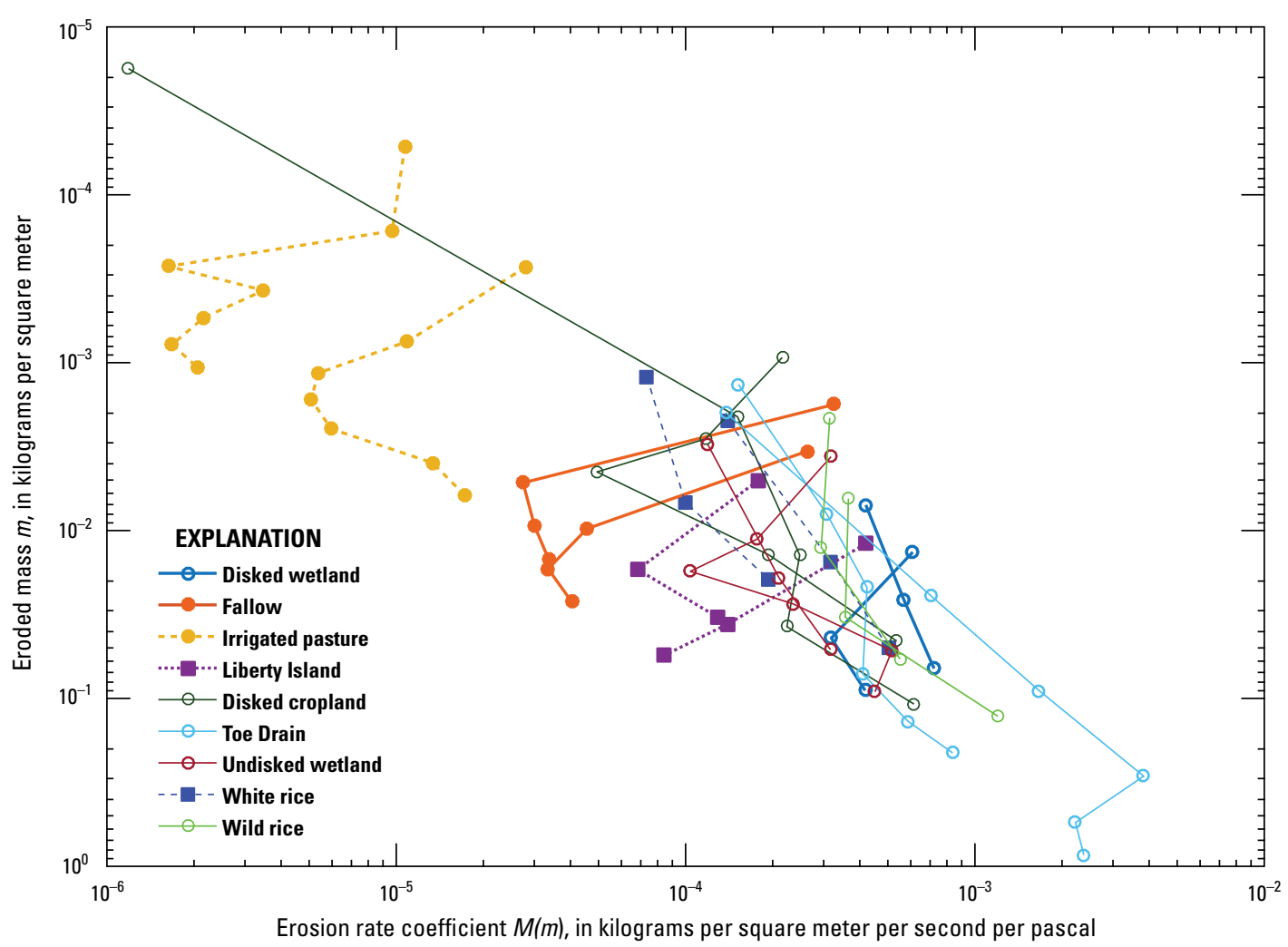

Figure 10. Erosion rate coefficient $M$ as a function of eroded mass. As with figure 9 , the $y$-axis can be viewed as a proxy for depth into the bed.

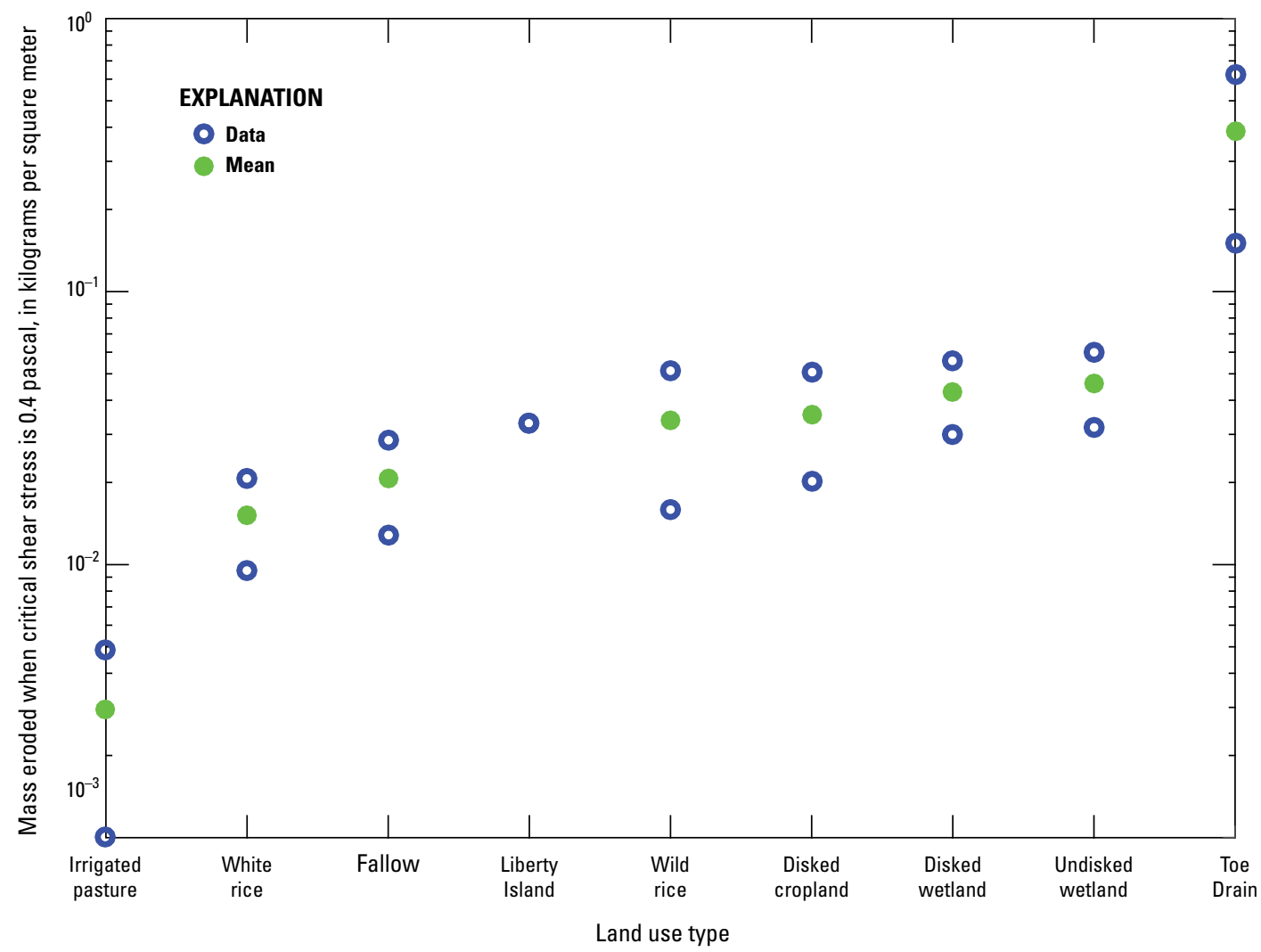

Figure 11. Mass eroded when the critical shear stress is 0.4 pascal ( $\mathrm{Pa})$. Blue circles are data for the individual cores, and green filled circles are the mean of the two values for each land use type. Land use types are ordered by increasing erodibility. Critical shear stress for one Liberty Island core never reached $0.4 \mathrm{~Pa}$ and is not shown. Note vertical scale is logarithmic. 

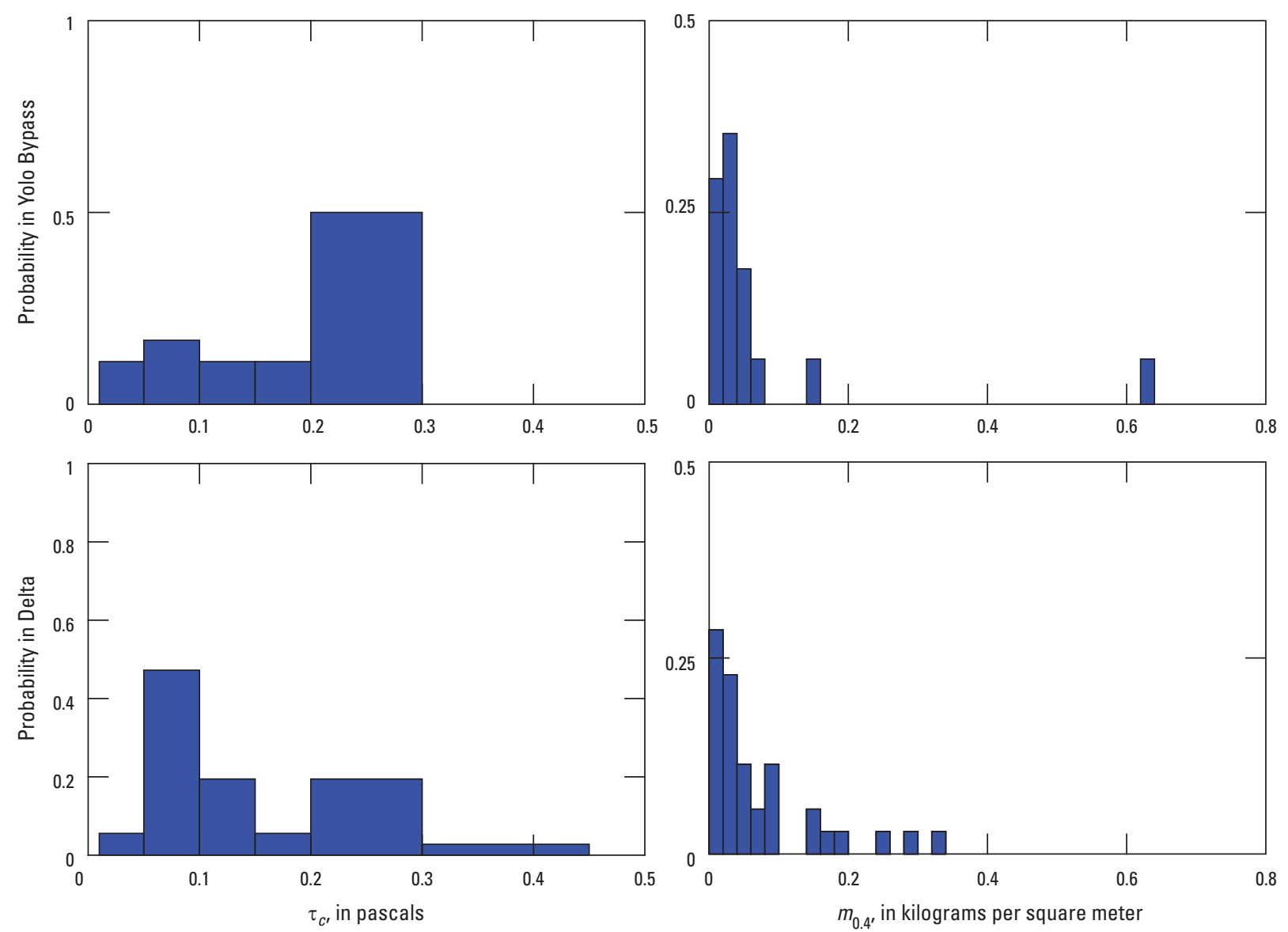

Figure 12. Probabilities of initial critical shear stress, $\tau_{c^{\prime}}$ and mass eroded when the critical shear stress is $0.4 \mathrm{~Pa}, m_{0.4^{\prime}}$ for (top pair of plots) the Yolo Bypass and (lower pair) 38 Sacramento-San Joaquin Delta subtidal cores analyzed 2011-14 (Schoellhamer and others, 2017).

Eroded mass increases approximately linearly as critical shear stress increases (figs. 9, 13). The incremental mass eroded when critical shear stress is increased by $\Delta \tau_{c}$ is $\mathrm{d} m / \mathrm{d} \tau_{c}$ $\times \Delta \tau_{c}$. For each land use, table 2 provides the two parameters $\left(\mathrm{d} m / \mathrm{d} \tau_{c}\right.$ and initial critical shear stress $\left.\tau_{c 0}\right)$ defining each best fit line.

$$
m=\left(\frac{d m}{d \tau_{c}}\right)\left(\tau_{c}(m)-\tau_{c 0}\right)
$$

where

$\tau_{c} \quad$ is the critical shear stress, varying with eroded mass,

$m \quad$ (which also implies depth-dependence), and

$\tau_{c 0} \quad$ is the initial value of this critical shear stress before any erosion occurs.
Equation 5 can be used to calculate erosion given an increase in the excess applied shear stress. Note that this approach is consistent with the idea that what happens to the sediment bed depends not only on conditions encountered at the time of interest but also on what happened to it in the past.

Table 2 ranks the land use types in order of decreasing $\mathrm{d} m / \mathrm{d} \tau_{c}$, so the Toe Drain is the most erodible land use (based on one result), and irrigated pasture is the least erodible land use. Of the land use types sampled, irrigated pasture displayed the lowest critical shear stress, meaning that it required the smallest flow speed to initiate erosion. But the rate of increase of the resulting erosion, given higher flow speeds, was small. The wild rice field sampled exhibited a higher critical shear stress, but also a much higher erosion rate, once the critical shear stress was exceeded. The erosion rate for wild rice was roughly three times greater than that for white rice. 


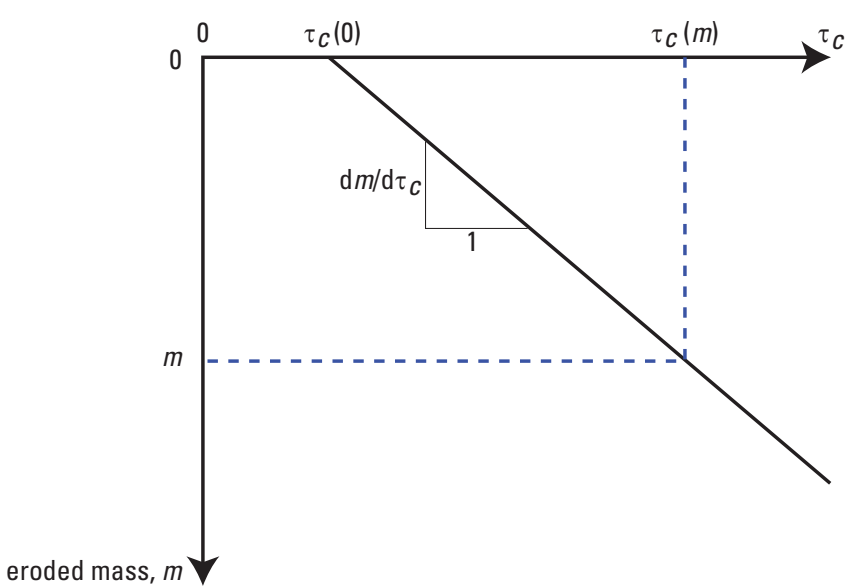

Figure 13. Eroded mass and critical shear stress $\tau_{c}$ are assumed to be linearly related with a slope of $\mathrm{d} m / \mathrm{d} \tau_{c}$. Once erosion commences, eroded mass begins to increase, as does the critical shear stress required for further erosion.

Table 2. Initial critical shear stress and slope of relation, $\mathrm{d} m /$ $\mathrm{d} \tau_{c^{\prime}}$ between eroded mass $(m)$ and shear stress for measured Yolo Bypass land uses, sorted in decreasing order of slope (soils at top are most erodible, once erosion is initiated).

[Each value is the mean of results for two cores obtained at the same site at the same time. Abbreviations: kg, kilogram; $\mathrm{m}^{2}$, square meter; Pa, pascal]

\begin{tabular}{lcc}
\hline \multicolumn{1}{c}{ Land use } & $\begin{array}{c}\text { Initial critical shear } \\
\text { stress } \boldsymbol{\tau}_{\mathbf{c}} \mathbf{P a}\end{array}$ & $\begin{array}{c}\mathbf{S l o p e ~} \mathbf{d} \mathbf{m} / \mathbf{d} \tau_{\mathbf{c}^{\prime}} \\
\mathbf{k g} / \mathbf{m}^{2} / \mathbf{P a}\end{array}$ \\
\hline Toe Drain & 0.075 & 1.27 \\
Wild rice & 0.25 & 0.429 \\
Disked wetland & 0.25 & 0.321 \\
Liberty Island & 0.25 & 0.276 \\
Disked cropland & 0.125 & 0.207 \\
Undisked wetland & 0.1625 & 0.194 \\
White rice & 0.25 & 0.142 \\
Fallow & 0.175 & 0.0832 \\
Irrigated pasture & 0.03 & 0.0084 \\
\hline
\end{tabular}

\section{Example: White Rice Field}

An example may help to illustrate the methodology. Assume a field used for white rice cultivation, experiencing an increase in flow that takes the flow speed from 0.3 to $0.5 \mathrm{~m} / \mathrm{s}$, while maintaining the water depth at $1 \mathrm{~m}$ for one hour, followed by a return to $0.3 \mathrm{~m} / \mathrm{s}$. The $D_{90}$ will be assumed to be 100 micrometers.
Per equations $1-3$,

$$
\begin{gathered}
k_{s}=3 D_{90}=300 \text { micrometers }=0.003 \mathrm{~m} \\
u^{*}=0.0190 \mathrm{~m} / \mathrm{s} \text { for } U=0.5 \mathrm{~m} / \mathrm{s}, \\
\text { and } 0.0114 \mathrm{~m} / \mathrm{s} \text { for } U=0.3 \mathrm{~m} / \mathrm{s} \\
\tau_{b}=0.361 \mathrm{~Pa} \text { for } U=0.5 \mathrm{~m} / \mathrm{s}, \\
\text { and } 0.130 \mathrm{~Pa} \text { for } U=0.3 \mathrm{~m} / \mathrm{s}
\end{gathered}
$$

For the white rice field, the critical shear stress was found to be $0.25 \mathrm{~Pa}$ (table 2). It is evident that the $0.3 \mathrm{~m} / \mathrm{s}$ flow would not be sufficient to mobilize the bed but that the bed would start to erode prior to the flow reaching $0.5 \mathrm{~m} / \mathrm{s}$ (at $U=0.42 \mathrm{~m} / \mathrm{s}$, specifically).

Also per table 2, once the erosion begins, the rate of change of eroded mass per increment of shear stress is $\mathrm{d} m / \mathrm{d} \tau_{c}=0.142$ kilograms per square meter per pascal $\left(\mathrm{kg} / \mathrm{m}^{2} / \mathrm{Pa}\right)$. In this case, erosion begins once $\tau$ reaches $0.25 \mathrm{~Pa}$, and the shear stress continues to increase to $0.361 \mathrm{~Pa}$. The effective change in the shear stress is thus $0.111 \mathrm{~Pa}$. Multiplying $\mathrm{d} m / \mathrm{d} \tau_{c}$ of 0.142 by $\Delta \tau_{c}$ of 0.111 Pa yields erosion of $0.016 \mathrm{~kg} / \mathrm{m}^{2}$. This is the amount of mass that will be eroded per unit area of bed surface if the applied shear stress of $0.361 \mathrm{~Pa}$ is held constant for a sufficiently long time. Per figure 8 , it is evident that $\sim 1,000$ seconds ( $\sim 15$ minutes) is required for the bed to respond to a newly increased shear stress. During this 15 minutes, the erosion rate would be decreasing to zero, until the shear stress increases again.

\section{Sediment Sample Analysis}

As a separate effort from the work described above, DWR provided USGS with 60 sediment samples from locations throughout the Yolo Bypass and asked for grain size analysis. This was done using a Coulter counter in the Sacramento sediment lab at the USGS California Water Science Center. Results were assembled in a Microsoft Excel spreadsheet provided to DWR. These data should be considered provisional.

Results include sample date and location, mass distribution by grain size, water content, loss on ignition, and median size. The geographical distribution of median grain size, loss on ignition, and percent fines in each sample are shown in figures 14-16. Sediments toward the northern end of the Yolo Bypass exhibit slightly finer median sizes, and the variability in sediment characteristics is greater near the southern end. 


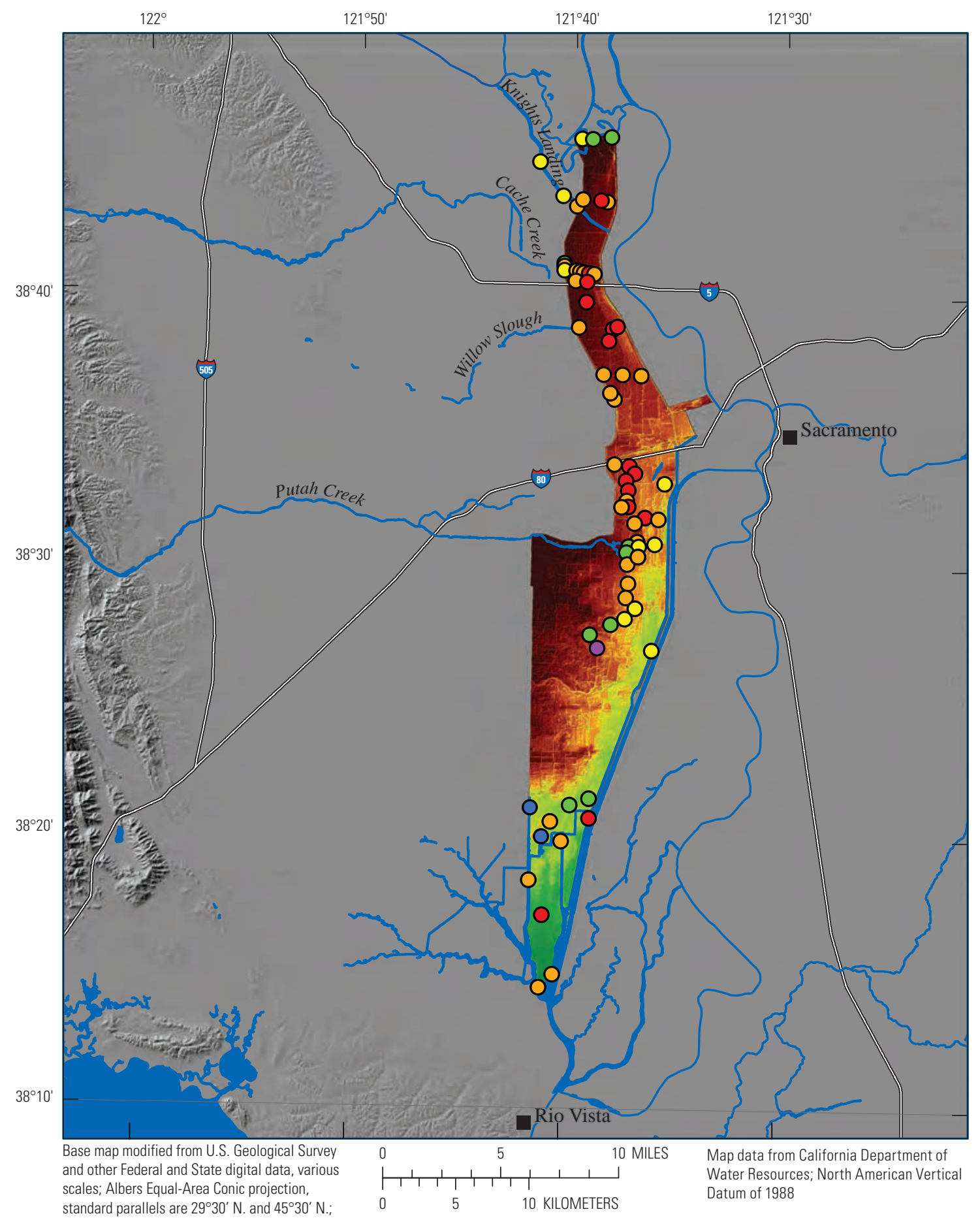

standard parallels are $29^{\circ} 30^{\prime} \mathrm{N}$. and $45^{\circ} 30^{\prime} \mathrm{N}$.

North American Datum of 1983

\section{EXPLANATION}

Median grain size, in micrometers

Elevation, in feet

Very fine silt (4 to 8) $\quad$ Coarse silt (>31 to 62)

Fine silt (>8 to 16) $\quad$ Very fine sand $(>62$ to 125$)$

Medium silt ( $>16$ to 31 ) Fine sand ( $>125$ to 250 )

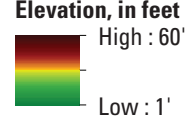

Figure 14. Median grain size for sediment samples collected in Yolo Bypass by the California Department of Water Resources. The coarse fraction (sizes greater than 1 millimeter) was separated and analyzed by sieving. The remaining sample was measured using a Coulter counter after the loss on ignition (LOI) measurement. 


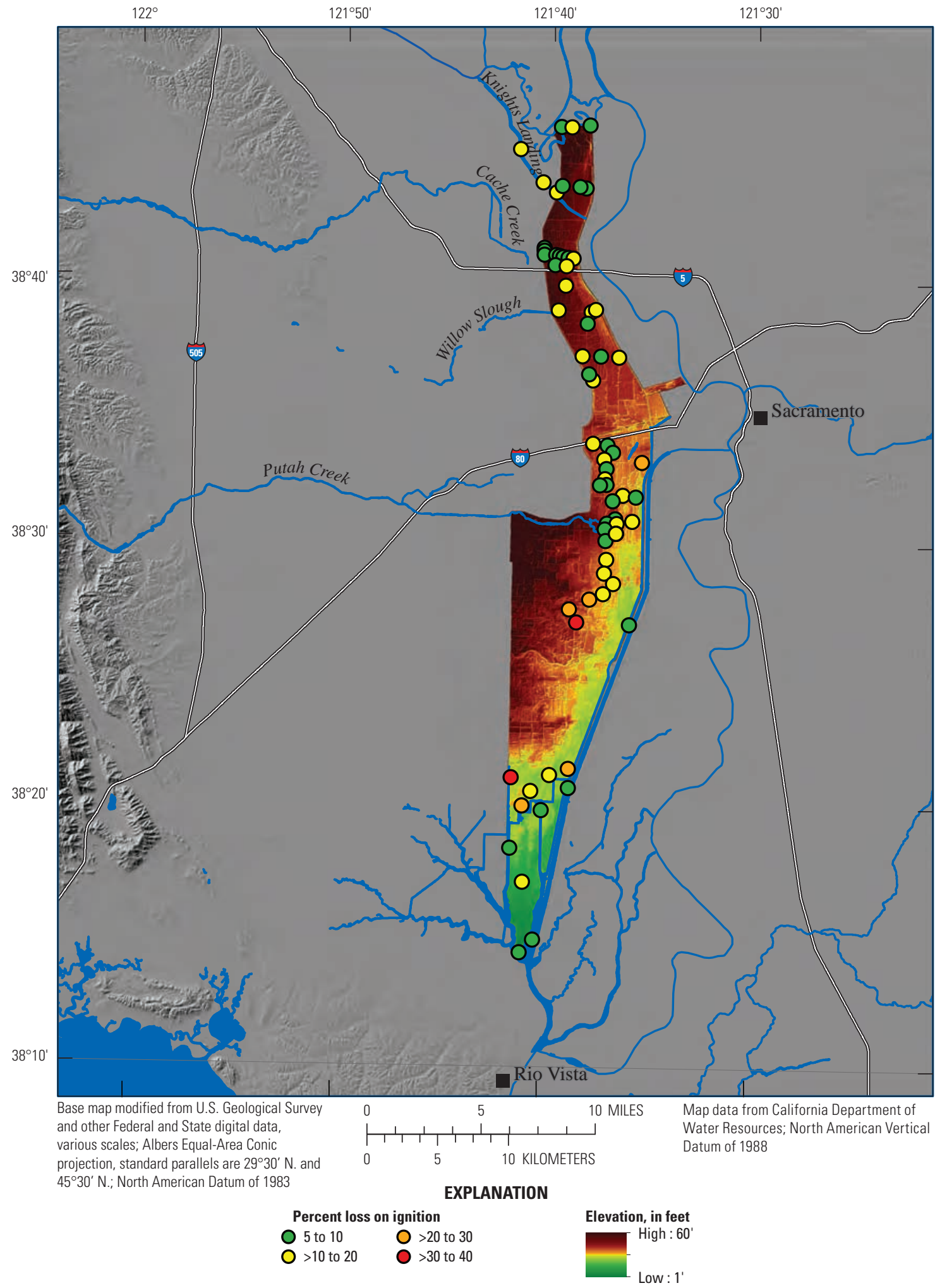

Figure 15. Loss on ignition for sediment samples collected in the Yolo Bypass by the California Department of Water Resources. 


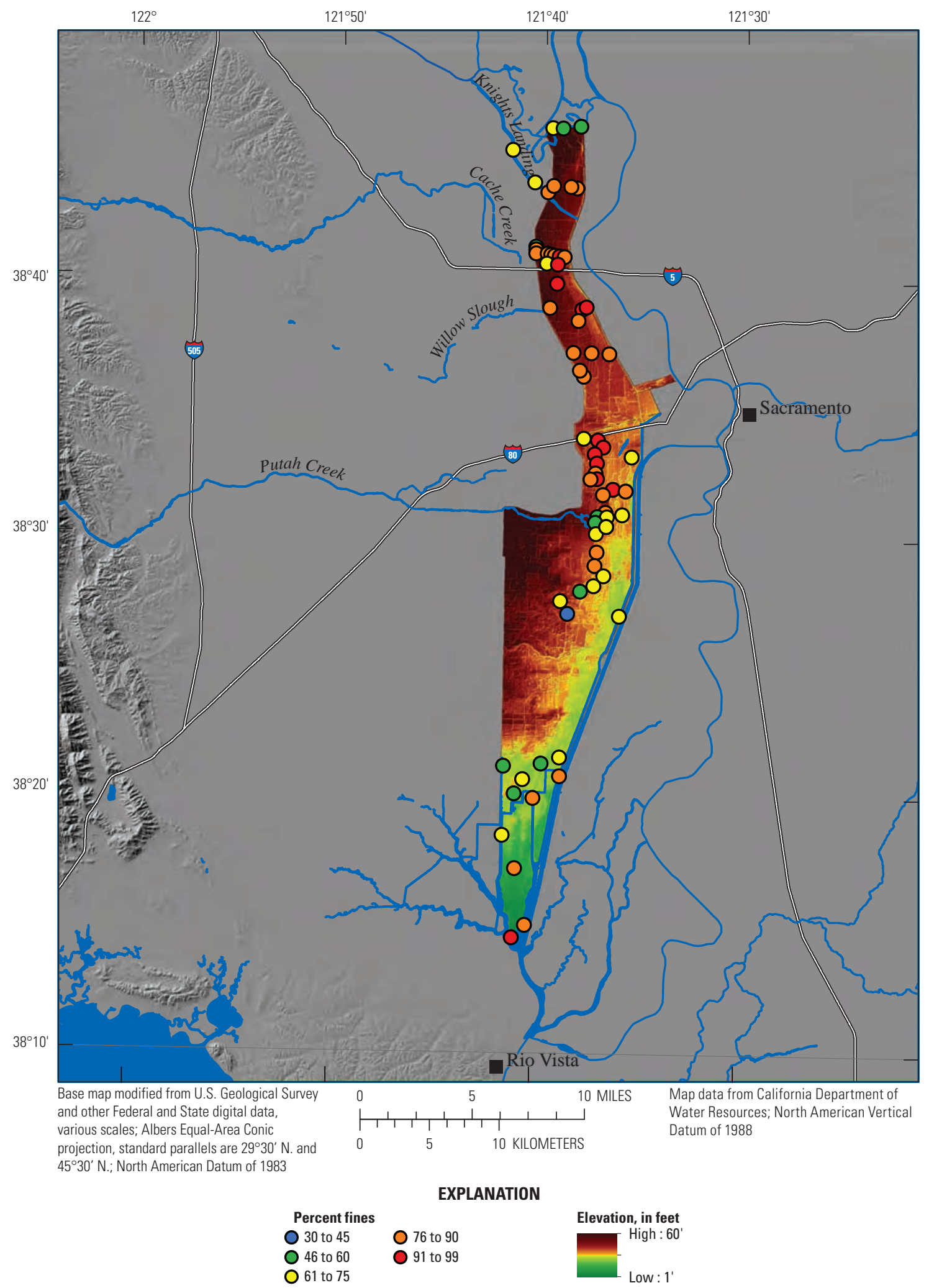

Figure 16. Percent fines for samples collected in the Yolo Bypass by the California Department of Water Resources. Fine sediment is defined to have a diameter less than 62 micrometers. 


\section{Conclusions}

To quantify the erodibility of Yolo Bypass soils, 10 locations were sampled, representing 10 land uses ranging from wild and white rice fields to the flooded Liberty Island and the Toe Drain. Results for each land use type tested are presented as the initial critical shear stress at which erosion began and the rate, or slope, at which erosion increased as shear stress increased (table 2). Of the land use types sampled, irrigated pasture displayed the lowest critical shear stress, meaning that it required the smallest flow speed to initiate erosion. But the rate of increase of the resulting erosion, given higher flow speeds, was small. The wild rice field sampled exhibited a higher critical shear stress, but also a much higher erosion rate, once the critical shear stress was exceeded. The erosion rate for wild rice was roughly three times greater than that for white rice. The spatial distribution of mean grain size, loss on ignition, and percent fines of Yolo Bypass soils are also presented.

\section{Recommendations}

The results presented here are being used to (1) simulate erosion within the Yolo Bypass in response to flow events and (2) quantify erosion rates as a function of these flows. In order to further refine the methodology and results presented here, three primary recommendations are made:

1. Increase the number of samples. Each land use that was considered was evaluated based only on one pair of cores obtained at one site at one time. Spatial and temporal variability can be significant and should be quantified. The only feasible means of doing this is by testing more samples and sites. It is recommended to have an absolute minimum of three samples per location (this would at least allow application of voting logic to provide minimal validation of measurements), and likewise, at least three locations sampled per land use type. This would imply an additional 30 coring and testing events. More would be required to allow computation of statistically significant means per land use.

2. Collect and test more cores in the Toe Drain and investigate both temporal and spatial variability there. A different coring method would be needed in some locations. This recommendation is made based on two observations: (1) the Toe Drain results exhibited both a low initial critical shear stress and a high subsequent erosion rate, and (2) given the Toe Drain's location and function, it is likely to receive sediment from adjacent areas and allow deposition once flood events subside.
3. The results from the numerical modeling of the flows and sediment transport should be validated through field measurements.

\section{References Cited}

Alpers, C.N., Fleck, J.A., Marvin-DiPasquale, M., Stricker, C.A., Stephenson, M., and Taylor, H.E., 2014, Mercury cycling in agricultural and managed wetlands, Yolo Bypass, California-Spatial and seasonal variations in water quality: Science of the Total Environment, v. 484, p. 276-287, doi:10.1016/j.scitotenv.2013.10.096.

Dickhudt, P.J., Friedrichs, C.T., Sanford, L.P., 2011, Mud matrix solids fraction and bed erodibility in the York River estuary, USA, and other muddy environments: Continental Shelf Research, v. 31, p. S3-S13.

Garcia, M.H., ed., 2008, Sedimentation engineering-Process, measurements, modeling, and practice: American Society of Civil Engineers, Manual of Practice 110, 1132 p.

Gust, G., and Muller, V., 1997, Interfacial hydrodynamics and entrainment functions of currently used erosion devices, in Burt, Neville, Parker, Reg, and Watts, Jacqueline, Cohesive sediments: New York, John Wiley and Sons, p. 149-174.

Sanford, L.P., and Maa, J.P.-Y., 2001, A unified erosion formulation for fine sediments: Marine Geology, v. 179, p. 9-23.

Schoellhamer, D.H., Manning, A.J., and Work, P.A., 2017, Erosion characteristics and horizontal variability for small erosion depths in the Sacramento-San Joaquin River Delta, California, USA: Ocean Dynamics, v. 67, no. 6, p. 799-811, accessed at https://doi.org/10.1007/s10236-017-1047-2.

Suttles, S., Sanford, L., and Dickhudt, P., 2011, Review, analysis, and recommendations for application of operation calibrations for UMCES-Gust erosion microcosm systems (U-GEMS): Easton, Md., Green Eyes Environmental Observing Systems technical report, $5 \mathrm{p}$.

Work, P.A., Schoellhamer, D.H., and Weidich, Kurt, 2016, Gust erosion chamber data, Yolo Bypass, CA (2015-16): U.S. Geological Survey data release, accessed at https://doi.org/10.5066/F7BV7DQC. 

Publishing support provided by the U.S. Geological Survey Science Publishing Network, Sacramento Publishing Service Center

For more information concerning the research in this report, contact the Director, California Water Science Center

U.S. Geological Survey

6000 J Street, Placer Hall

Sacramento, California 95819

https://ca.water.usgs.gov 


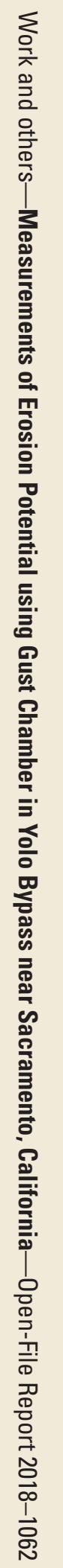

